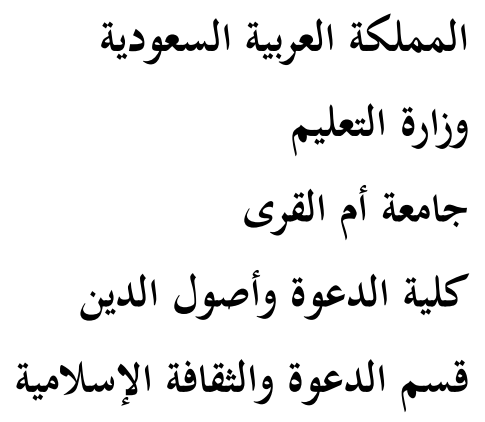

جون إسبيزتو

\title{
John Esposito
}

وموقفه من الثقافة الإسلامية

إعداد: عبد الله بن علي بن أحمد القرني. 


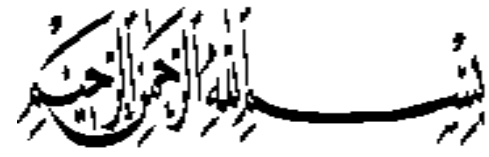

الحمد لله رب العالمين ، منّ علينا بأن جعلنا من المسلمين ، وأرسل إلينا خير الأنبياء

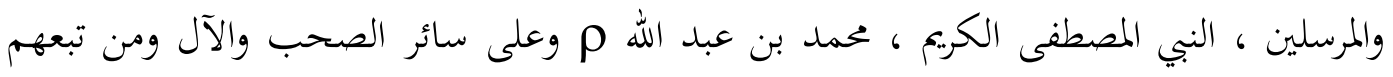

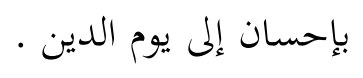

أما بعد:

فهذه مباحث عن سيرة وكتب المستشرق الدكتور جون اسبيزتو ، وما يتعلق بمكانته العلمية

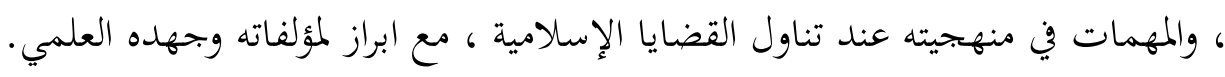

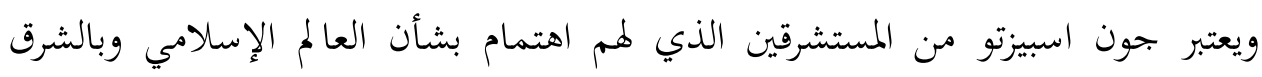
الأوسط على الأخص، وظهر ذلك في الكثير من كتاباته ومشاركاته الإعلامية.

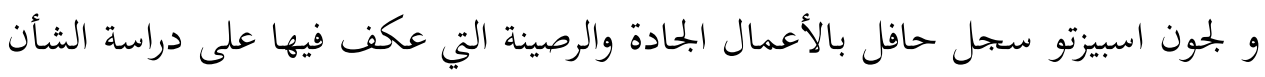

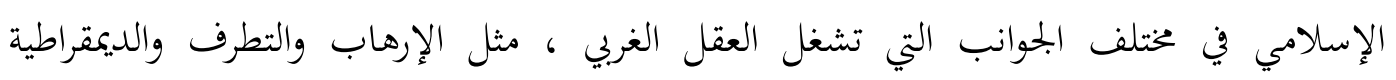

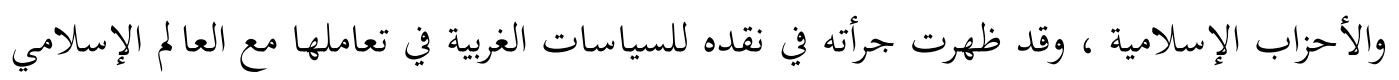
،وأها سبب رئيس في المشاكل التي ظهرت في العالم الإسلامي في العصر الحديث.

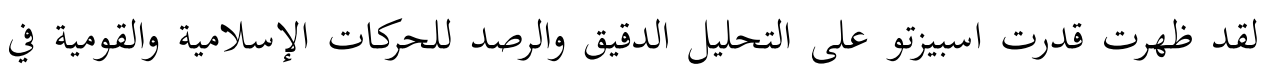

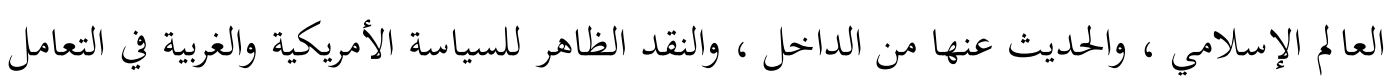

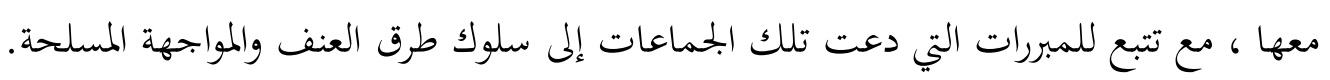

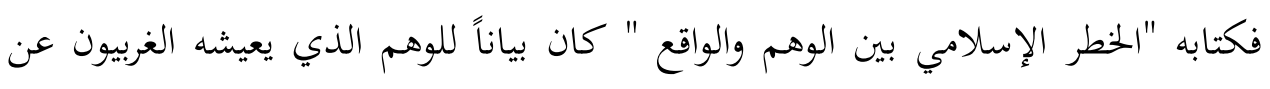

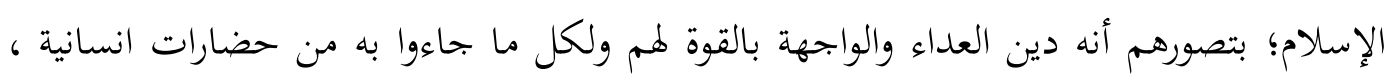

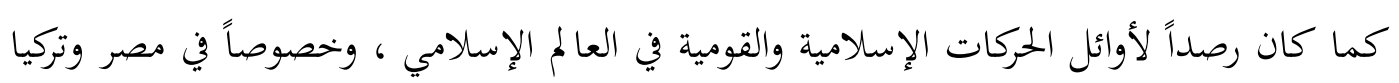
وإيران.

وفي كتابه " الحرب غير المقدسة الإرهاب باسم الإسلام" والذي ظهر بعد احداث الحادي

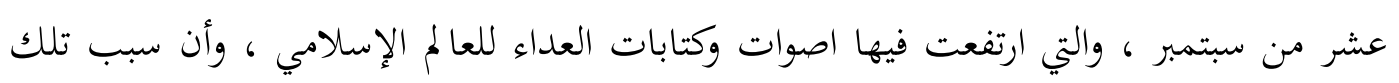

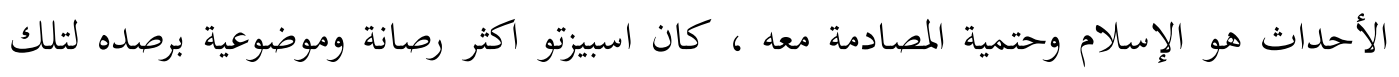

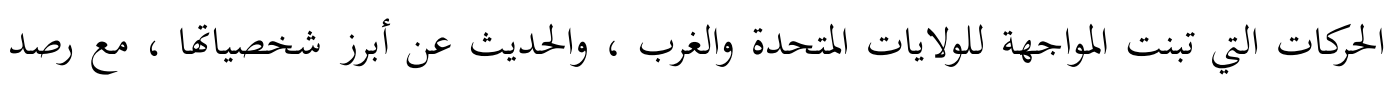


لأعمالها وخططها ، وأفها طيف واحد أورثته سياسات الغرب واقصائه وتميشه للمسلمين ،

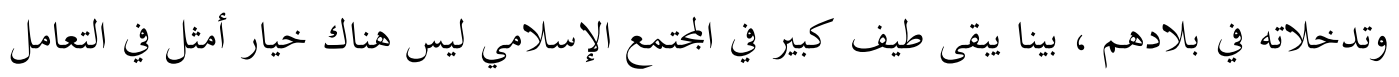

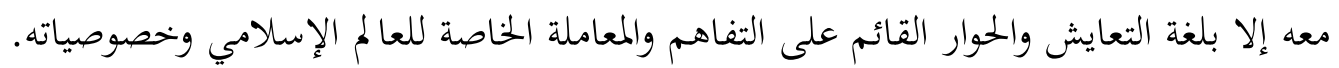

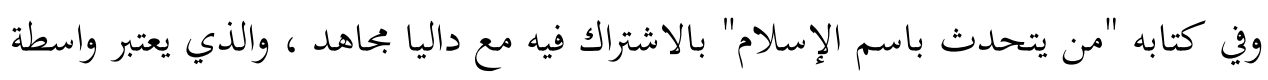

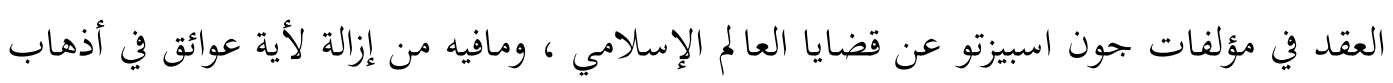

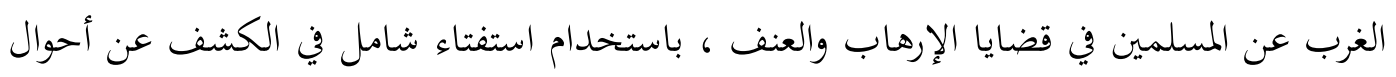

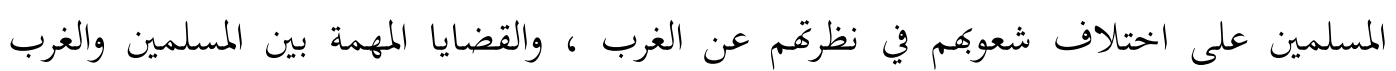

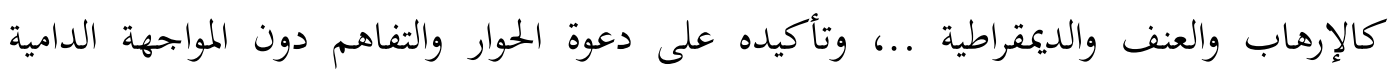
لمسلمين.

لقد استطاعت الآلة الإعلامية أن تنبت بذور الحساسية والنفور من الإسلام والمسلمين

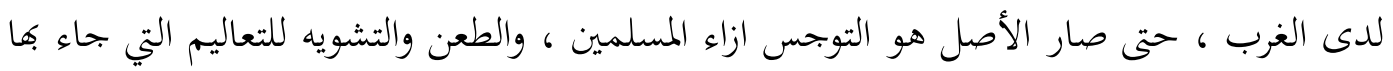

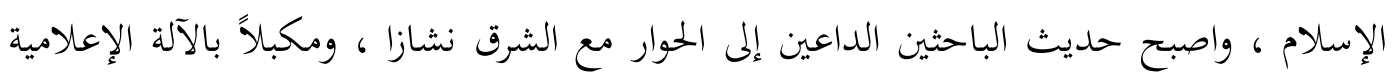

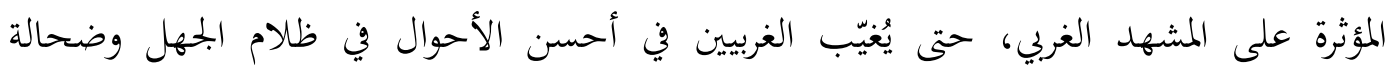

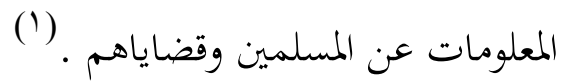
واستطيع القول بعد أمعان وطول نظر في مؤلفات الدكتور جون اسبيزتو الماضية، والموجهة

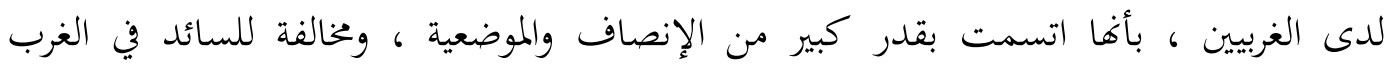

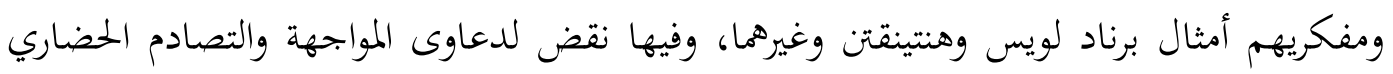

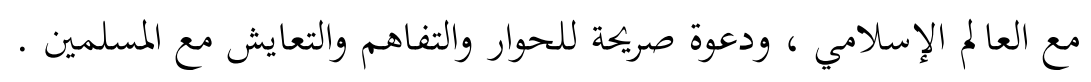

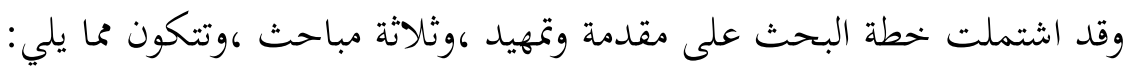
O المقدمة ، وفيها بيان لمكانة جون اسبيزتو ومؤلفاته. O التمهيد، وفيها: أولاً: التعريف بجون اسبيزتو وسيرته الذاتية والعملية. ثانياً: منهجيته العلمية.

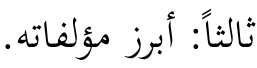


O المبحث الأول : كتاب "الخطر الإسلامي بين الوهم والواقع" ، وفيه المطالب التالية:

المطلب الأول : التعريف بالكتاب وعرض أهم الرؤى والأفكار. المطلب الثاني: المنهج المتبع في الكتاب.

المطلب الثالث: نظرة جون اسبيزتو للثقافة الإسلامية من خلال كتابه الخطر الإسلامي بين الوهم والحقيقة. المبحث الثاني : كتاب "الحرب غير المقدسة الإرهاب باسم الإسلام" ، وفيه المطالب التالية: المطلب الأول : التعريف بالكتاب وعرض أهم الرؤى والأفكار. المطلب الثاني: المنهج المتبع في الكتاب. المطلب الثالث: نظرة جون اسبيزتو للثقافة الإسلامية من خلال كتابه الحرب غير المقدسة:

O مبحث الأول : كتاب "من يتحدث باسم الإسلام" لمؤلفه جون اسبيزتو وداليا

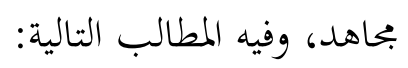
المطلب الأول : التعريف بالكتاب وعرض أهم الرؤى والأفكار. المطلب الثاني: المنهج المتبع في الكتاب. المطلب الثالث: نظرة جون اسبيزتو للثقافة الإسلامية من خلال كتاب من يتحدث

$$
\text { باسم الإسلام. }
$$

وآخر دعوانا أن الحمد لله رب العالمين ، وصلى الله وسلم وبارك على نبينا محمد وعلى آله وصحابته ومن تبعهم بإحسان إلى يوم الدين. التعريف بالدكتور جون اسبيزتو وجهوده ومؤلفاته:

أولاً سيرته الذاتية والعملية ا :

/http://explore.georgetown.edu/people/jle2 انظر : ترجمته في موقعه على الإنترنت /http://ar.wikipedia.org/wiki 
ولد جون اسبيزتو في 91 مايو • ـو 19، في بروكلن، بمدينة نيويورك، وترعرع كاثوليكيَّا

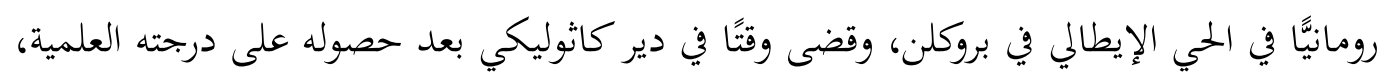

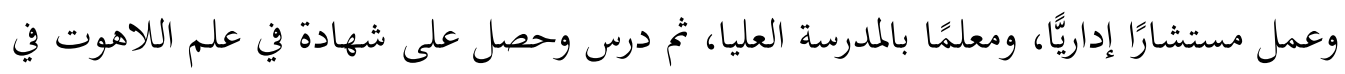

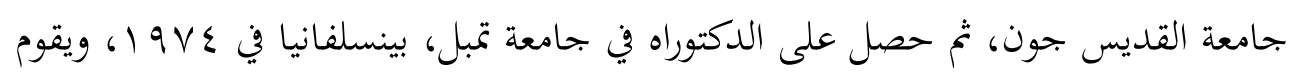

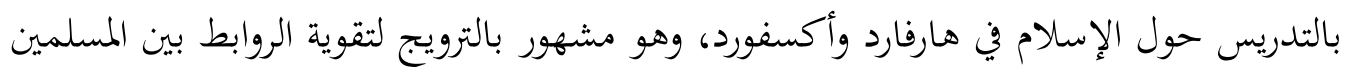
والمسيحيين.

حياته العملية:

بعد حصوله على الدكتوراه قام اسبيزتو لمدة عشرين سنة تقريبًا بتدريس الدراسات الدينية

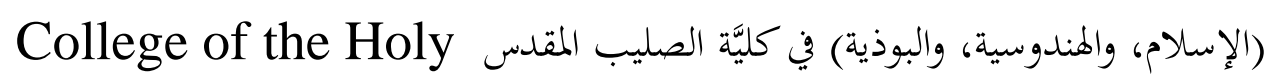
Cross

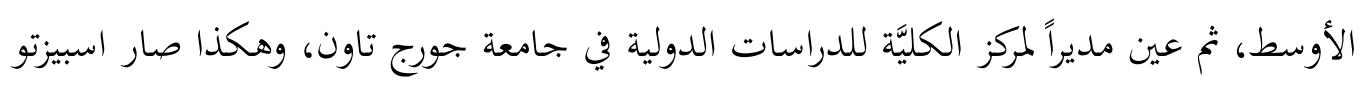
أستاذ جامعة، وأستاذ الدين والشؤون الدولية، وأستاذ الدراسات الإسلامية.

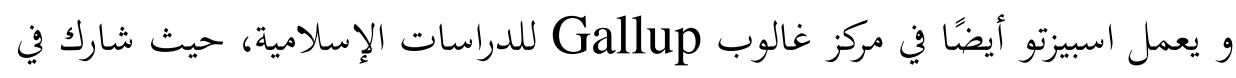

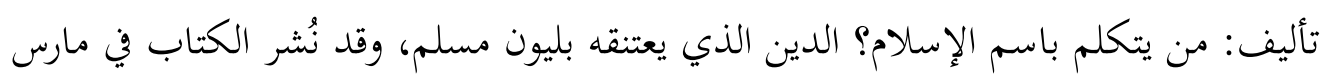
.r..人

كما أسس مركزاً للتفاهم الإسلامي المسيحي في جامعة جورج تاون - وهو مديره الحالي-

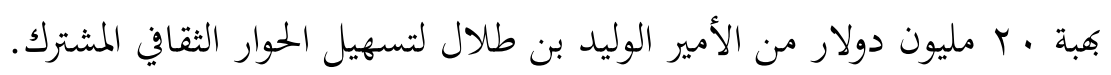

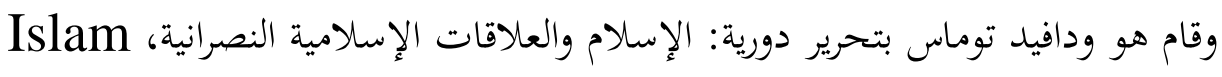

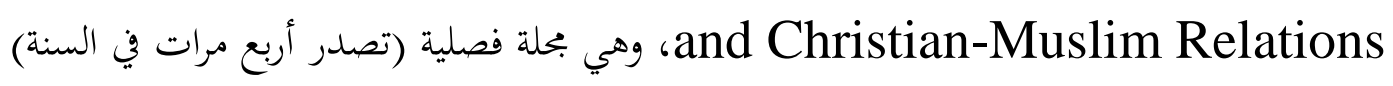
عن مركز دراسة الإسلام والعلاقات الإسلامية -المسيحية، برمنغهام-إبخلترا. أهم أعماله:

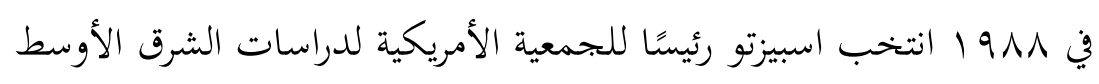
MESA

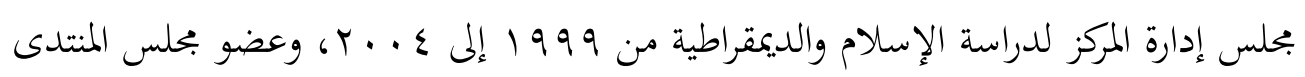


الاقتصادي العالمي بالمحموعة العالية لتحالف حضارات الأُمم المتّحدة، وحصل على كثير من

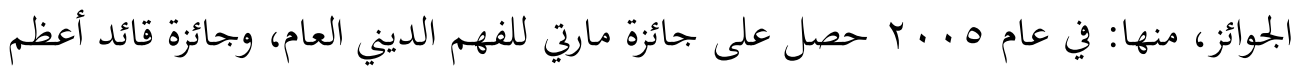
الباكستانية لمشاركاته في الدراسات الإسلامية.

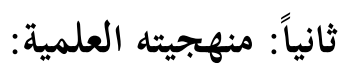

يعتبر جون اسبيزتو من الكتاب المستشرقين الذين حاولوا الحديث عن الإسلام وقضاياه

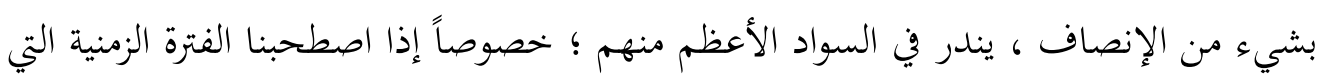

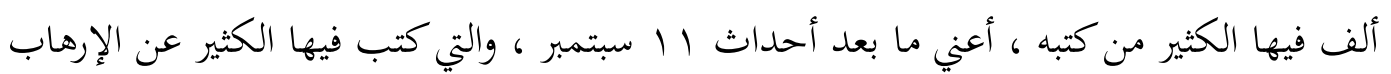
في الإسلام ، وحتمية صراع الحضارات ، ونخو ذلك.

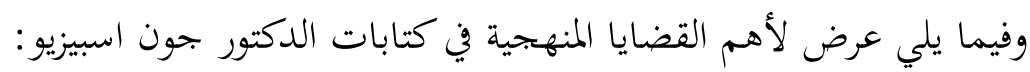

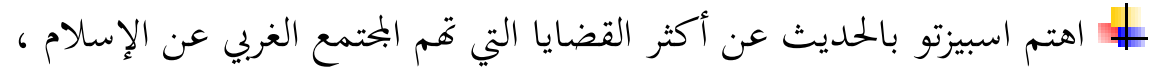
مثل قضايا الإرهاب والتطرف الإسلامي ، ونظرة المسلمين عن المختمعات الغربية.

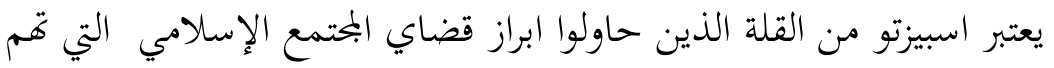

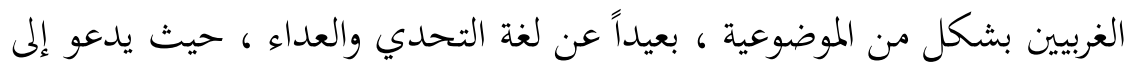
فهم العرب والمسلمين على نخو أفضل بعيداً عن الصور والأحكام المسبقة. من الأخطاء التي حدثت في كتابات اسبيزتو استصحابه لمسمى العصور المظلمة في حديثه عن عصر العلماء السابقين كشيخ الإسلام ابن تيمية، وتسميته

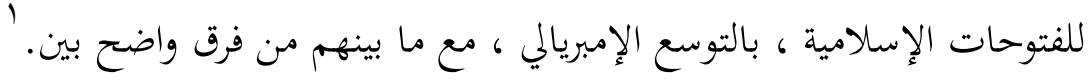

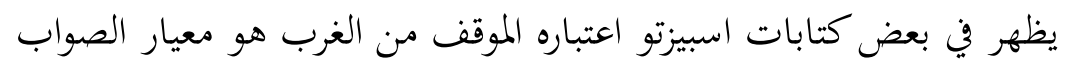

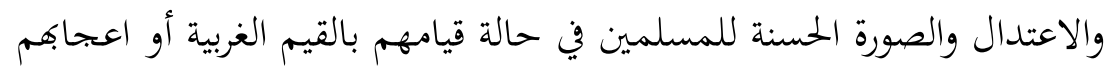
ك. | تظهر الاهتمامات السياسية للمجتمع العربي لدى اسبيزتو ، في كتبه ومشاركاته

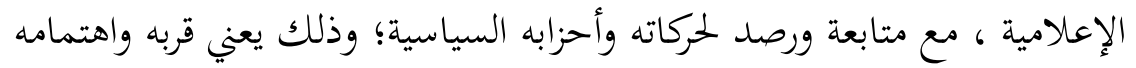

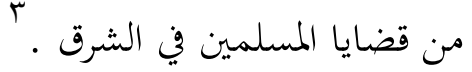


معلومات اسبيزتو عن الطائفة الشيعية ، وبعض قضايا الخلاف بينها وبين أهل

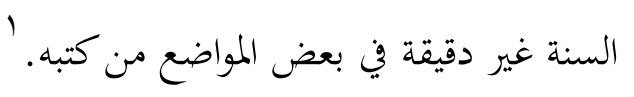

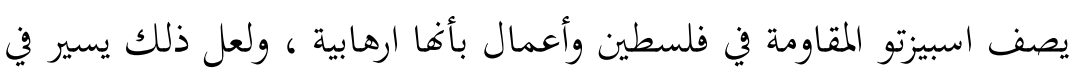

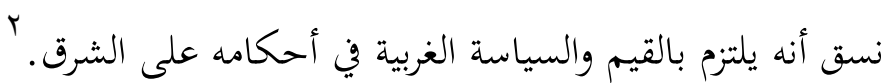

ثالثاً : أهم مؤلفاته: - n

قدم اسبيزتو كتبًا كثيرة تناولت الإسلام من عدة جوانب، كان من أهمها "التهديد

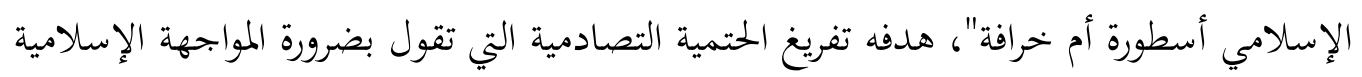

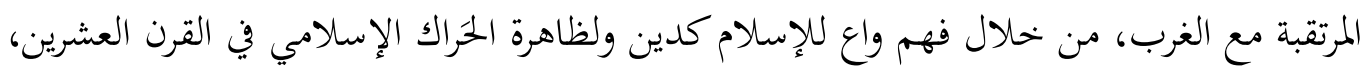
حرر اسبيزتو كتبًا بمفرده، وشارك في تحرير كتب أخرى، منها:

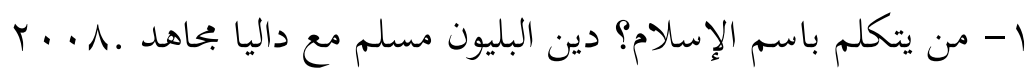

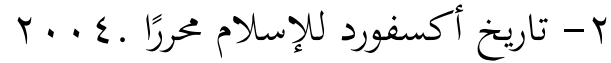

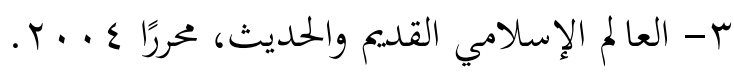

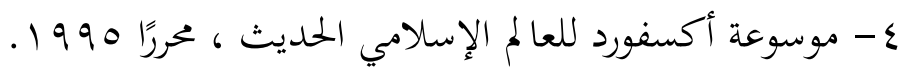

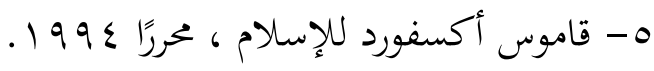

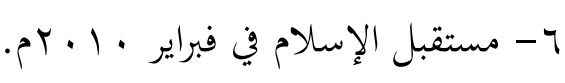

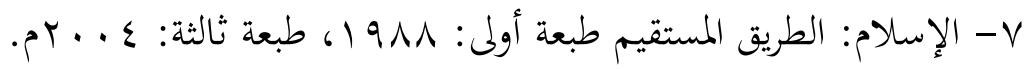

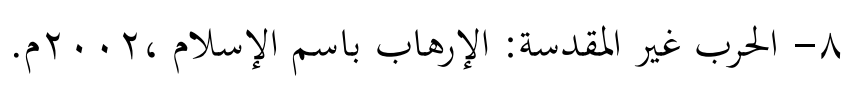

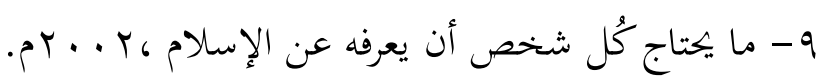

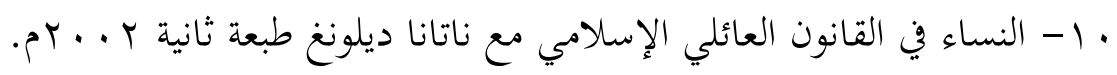

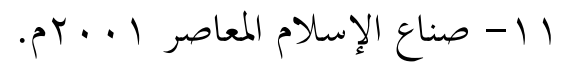

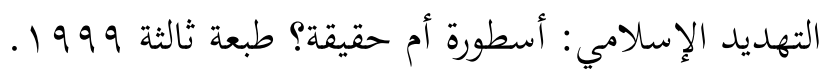

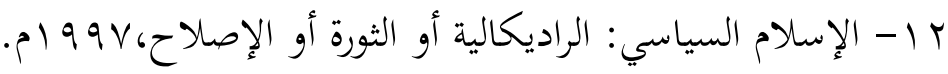

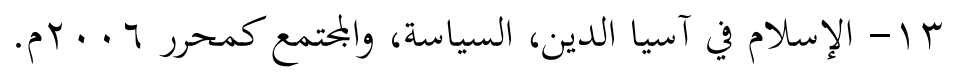

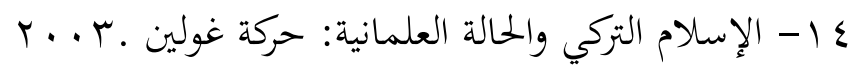


ما - تحديث الإسلام: الدين في المحال العام في الشرق الأوسط وأوربامع فرانسوا وبرغات

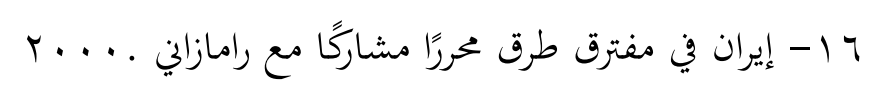

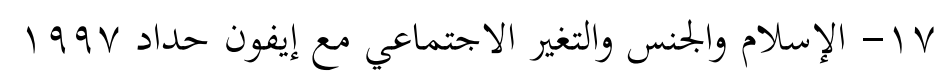

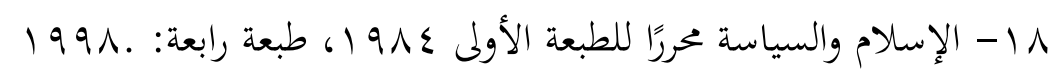

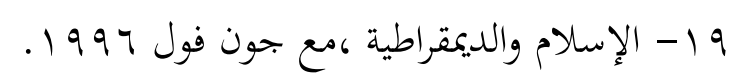

المبحث الأول : كتاب "الخطر الإسلامي بين الوهم والواقع" ، وفيه المطالب

التالية:

المطلب الأول : التعريف بالكتاب وعرض أهم الرؤى والأفكار:

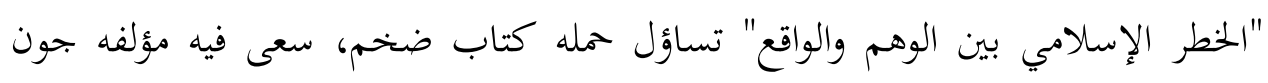

اسبيزيتو في محاولة جادة وطموحه للإجابة عنه باجابة شاملة ووافية ، مع الالتزام بالحياد والموضوعية.

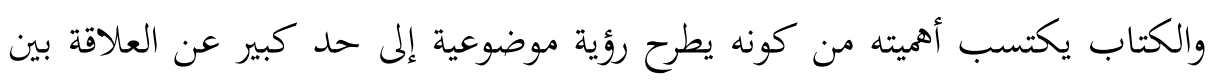

الإسلام والغرب ، وفيه رد على كثيراً من المقالات والكتابات التي تدين الإسلام والعاملين باسمه دئه

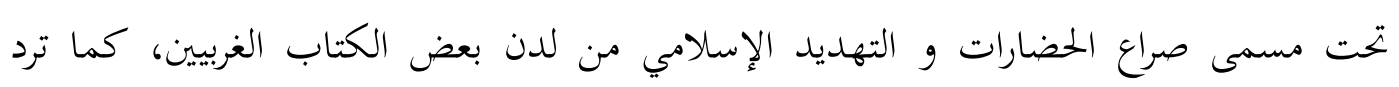

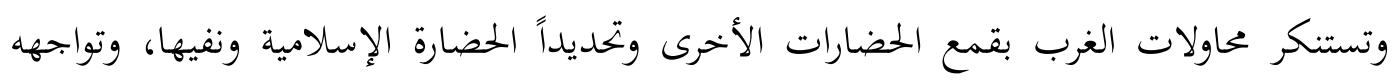
بالتحدي بحقيقة وجود هذه الحضارة وقدرتها على أن تستوعب كافة المنجزات الحديثة.

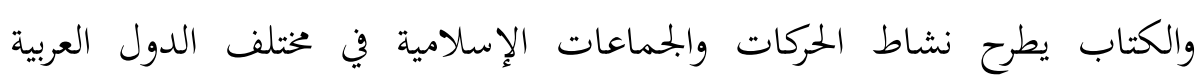

والإسلامية مع نقد ظاهر لسياسة الغرب والمستغربين في التعامل معها.

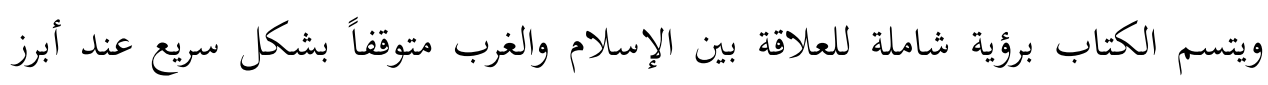

محطاها قديماً وذلك بالقياس إلى العصر الحديث.

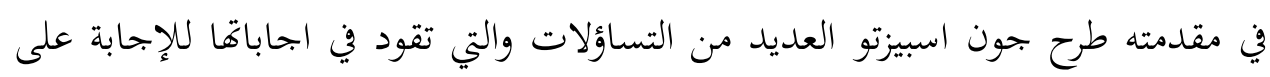

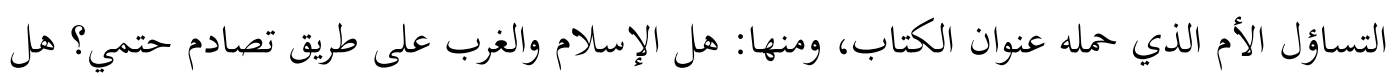

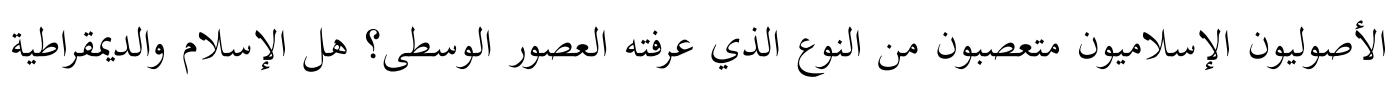

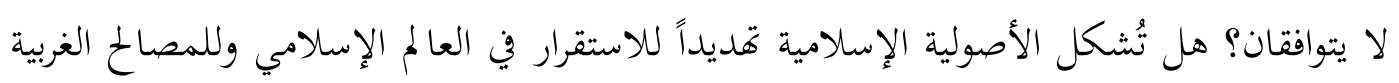
في المنطقة؟ 
ومنذ البداية يعلن الدكتور اسبيزتو رفضه للمبالغة الغربية في تشويه طبيعة الإسلام والحقائق السياسية في العالم الإسلامي، وعلاقتها المختلفة مع الغرب؛ حيث تكرس هذه المبالغة درجة مدهشة من الجهل والتنميط الثقافي للعرب والمسلمين. وفي الفصل الأول من ستة فصول يضمها الكتاب "الإسلام المعاصر: إصلاح ديني أم ثورة" يضع اسبيزتو رؤية عامة للركائز الأساسية في الإجابة عن تساؤله "التهايد الإسلامي وهم أم واقع"، بداية من معاودة الإسلام الظهور باعتباره قوة عالمية محتملة خلال السبعينات والثمانينات من القرن العشرين، وذلك في اشكال عدة متباينة في ارائها وأطروحاتما للحركات والجماعات الإسلامية في البلدان العربية والإسلامية، سواء كانت هذه الحركات تعمل من داخل النظام السياسي أو كانت حركات راديكالية، ويستعرض الأسباب التي أدت إلى بروز هذه الحركات، واحتدام العلاقة مع

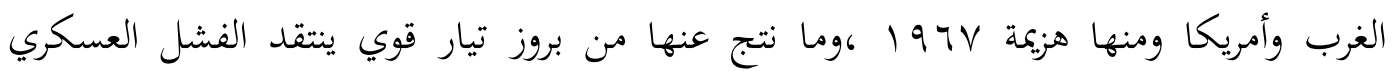
والثقافي والاجتماعي الذي جلبه التطوير الذي يستهدي بالغرب. (') وفي الفصل الثاني "الإسلام والغرب: جذور الصراع والتعاون والمواجهة" ،حاول اسبوزتو أن يعطي خلفية تاريخية عن الإسلام منذ نزول الرسالة، والأسس التي يقوم عليها ومدى تأثيرها على

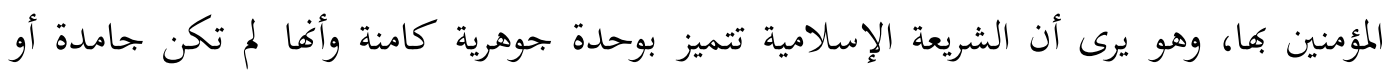

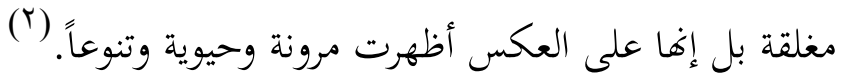
كما يأتي في الفصل الثالث "الغرب الظافر: وردود أفعال المسلمين" ليبين أن قوة الغرب هي التي حكمت النظرة العالمية للاستعمار الأوروبي، وقدمت مبررا جاهزا للاستعماريين والمبشرين المسيحيين الذين صاروا جنود الطليعة للتوسع الأوروبي والهيمنة الإمبريالية في العالم الإسلامي، الأمر الذي تولدت عنه حركات التجديد الإسلامي منذ القرنين الثامن والتاسع عشر في شتى أرجاء العالم الاسلامي، حيث وجد المسلمون انفسهم في موقف دفاعي إزاء التوسع الأوروبي بشكل مطرد، إذ أصبح الغرب في أواخر القرن التاسع عشر وأوائل القرن العشرين يشكل تحدياً للمسمين على الى المستوى السياسي والاقتصادي والأخلاقي والثقافي لقد "هدد الاستعمار والإمبريالية الهوية السياسية والدينية والثقافية الإسلامية وتاريخها "(")

$$
\begin{aligned}
& \text { (1) انظر: الخطر الإسلامي بين الوهم والواقع،(ب (1-1). }
\end{aligned}
$$

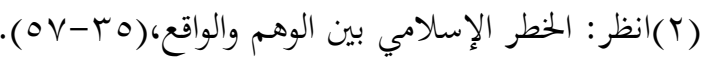

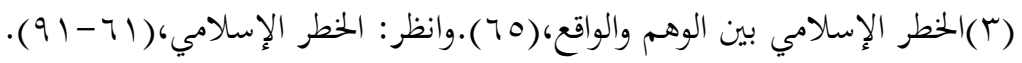


وقد حدد اسبيتو أربع استجابات إسلامية للتحدي الذي طرحه الغرب: الرفض (1)

والانسحاب والعلمانية والتحديث والحداثة الإسلامية. (')

أما في الفصلين الرابع "الإسلام والدولة دينامية الانبعاث "(r) والحنامس الإسلة "المنظمات

الإسلامية : جند الله"(َ) فيستعرض الدكتور جون اسبيزتو ما حدث في أربع دول هي ليبيا

والسودان ومصر وإيران على الرغم من الاختلاف الظاهر في وضعية هذه البلاد في الكثير من المستويات بما فيها المستوى الديني، والأحداث التي ألقت بظلالها عليها، وأثرت سلباً على صورة

وفي الفصل السادس "الإسلام والغرب : صراع الحضارات" يحاول فيه الدكتور اسبيزتو جمع

العديد من الخيوط التي تشابكت عبر فصول الكتاب السابقة؛ لكي تضع النقاط على الحروف فيما

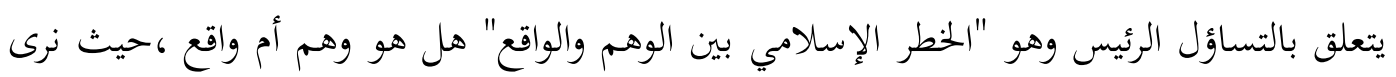

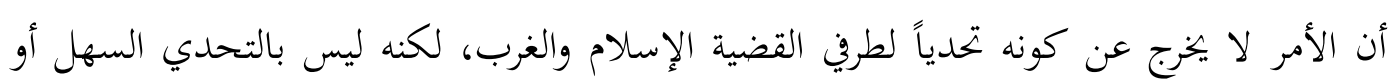

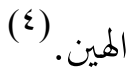

ويضيف جون اسبيزتو: أن الاسلام المعاصر يشكل تحديا اكثر منه تمديداً اذ إنه يتحدى

الغرب أن يعرف وأن يفهم التجربة الاسلامية، ثم ينتقد العالم الأمريكي و الرؤية الغربية والأمريكية القائمة على التهويل والتحريض والمبالغة غير الحقيقية للخطر الإسلامي على الغرب، سواء جاءت

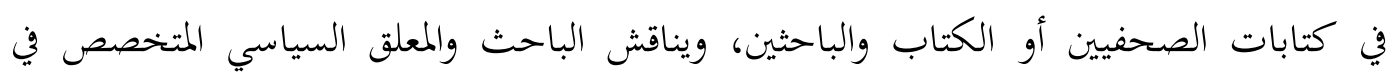
الشرق الأوسط برنارد لويس وكتابه "الأصولية الإسلامية" رافضاً ما قدمه من صورة صادمة للإسهلام والمسلمين باعتبارهم أصولين، ومقاتلين خطرين، مهياً بذلك القارئ الغربي ليرى علاقة الإسلام بالغرب في ضوء الغضب والعنف والكراهية واللاعقلانية. وكذلك الباحث صموئيل هنتينغتن وكتابه

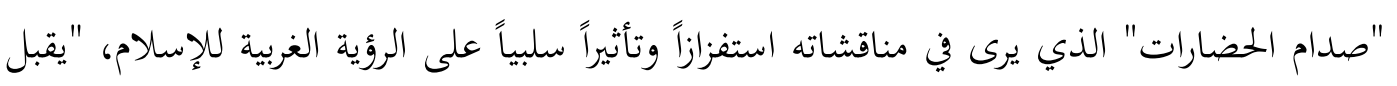

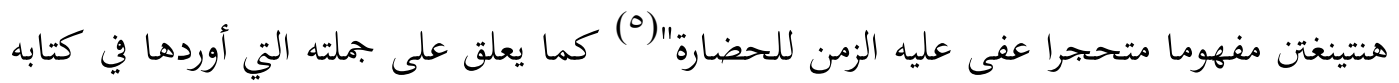

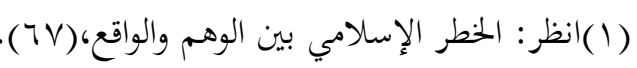

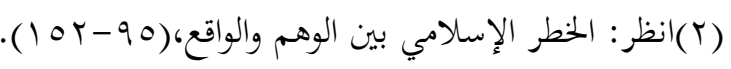

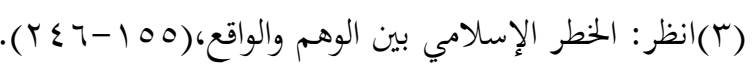

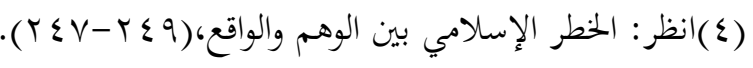

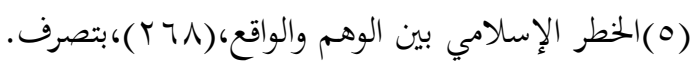


هذا "الإسلام له حدود دموية (')" والتي خصص لها فصلا في كتاب آخر له بعنوان "صدام الحضارات وإعادة صنع النظام العالمي" فيرى اسبيزتو أن هذه العبارة تربط بشكل سلبي بين الدين

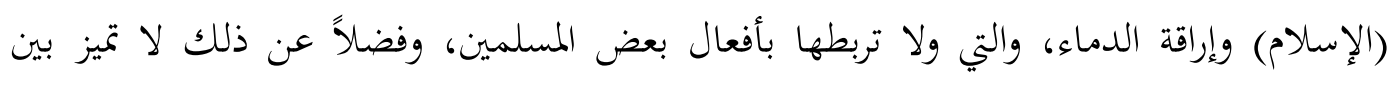
الاستخدام المشروع للقوة وبين الاستخدام غير المشروع لما. وتبقى الكثير من التفاصيل المهمة التي استوعبها هذا الكتاب الضخم والمجهود الرائع المبذول فيه والتي تؤكد على أهمية تغيير الغرب لنظرته

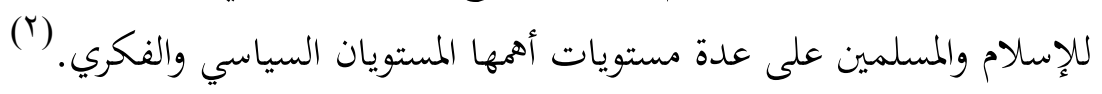
والكتاب طبع في أول طبعاته عام: بو 19 1م ، وتمت إعادة طرحه بعد الإضافة والتعديل نتيجة العديد من المستجدات والتطورات المرتبطة بنشاط الحركات الإسلامية على الساحة المحلية العربية والإسلامية والعالمية مرتين بعد ذلك في عام 990 ام ، وعامج9 99 ام.

$$
\begin{aligned}
& \text { وترجمه هيثم فرحات ، وطبعته دار الحوار بسورية عام . T. } \\
& \text { المطلب الثاني: المنهج المتبع في الكتاب: }
\end{aligned}
$$

اعتمد المؤلف على المنهج الوصفي والتاريخي النقدي في حديثه عن علاقة العالم

الإسلامي بالغرب، وما تبع ذلك من المواقف و الأحداث والمشاهدات التي امتلأ الكتاب بسردها وتوصيفها ـوفيما يلي بيان بأهم النقاط في منهج المؤلف في كتابة الخطر الإسلامي بين الوهم والواقع:

تتبع الكاتب الحركات الإسلامية ، والقومية العربية ، وما اشتملت عليه من اختلاف في الطيف الإسلامي ، ومدى تأثير ذلك في نظرة الغرب للإسلام والمسلمين. اثارة الاسئلة المؤثرة و الجريئة و المتتابعة ، والتي تكشف لإسئ لأذهان الكثير من المسائل المشكلة ، ومحاولة الإجابة عنها بكل انصاف وموضوعية وشمول في الغالب. حاول الكاتب ابراز كيف كان حال المسيحيين واليهود في عهد الحكم الإسلامي بشيء من الإنصاف والموضوعية ، يقول اسبيزتو:"لم تتعرض الكنائس والسكان المسيحيون بالعودة للمضايقة ... وسمح لليهود الذين حُظر عليهم العيث هناك على أيدي الحكام المسيحيين

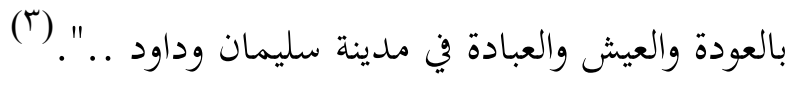

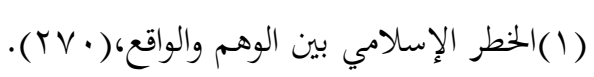

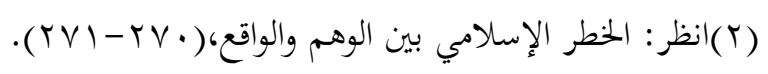

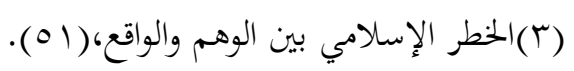


ظهر لدى الكاتب النقد المتكرر للنظرة الغربية عن الإسلام والمسلمين ، والتي اشتملت على

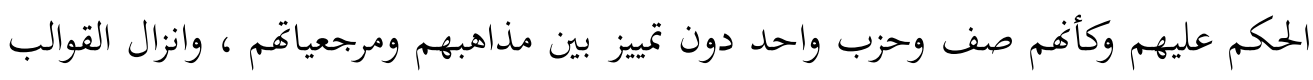

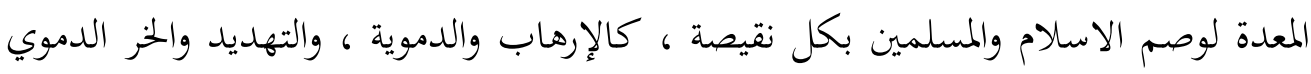

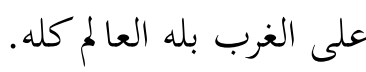

المطلب الثالث: نظرة جون اسبيتو للثقافة الإسلامية من خلال الخطر الإسلامي

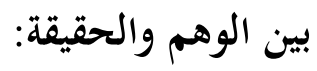
حسن عرضه للعقلية الغربية ، وطريقة تفكيرها ونظرتما عن الإسلام والمسلمين ، والحركات

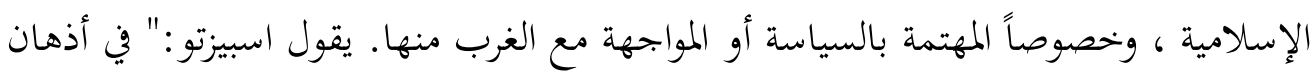

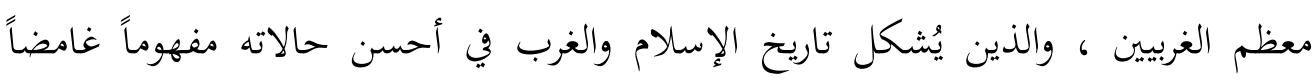
بالنسبة إليهم ،تبلورت معرفة الإسلام والعالم الإسلامين والموقف منهما عن طريق تصورات

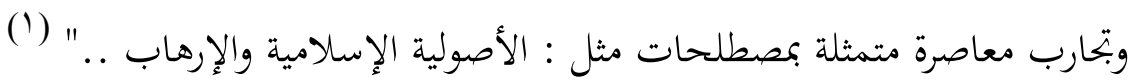

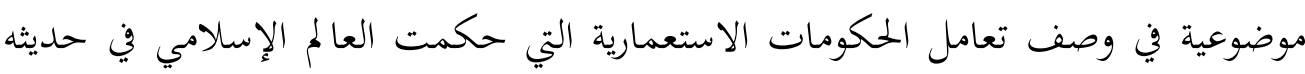

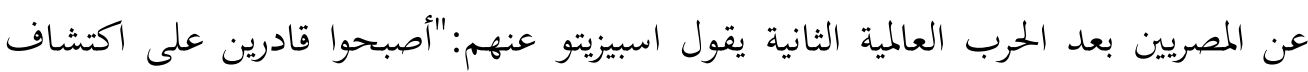

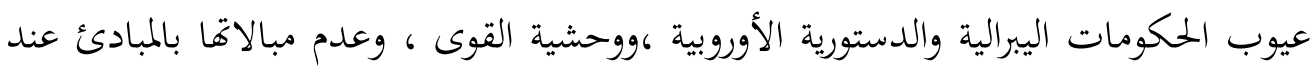

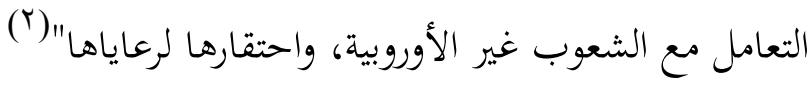

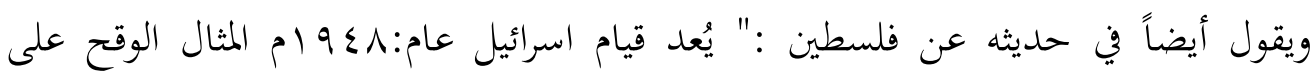

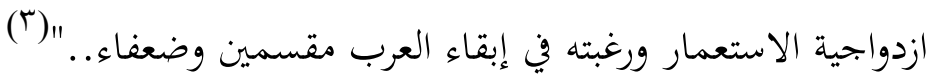

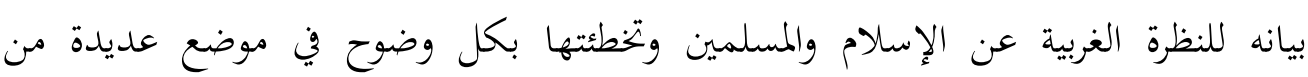

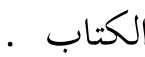
مخالفته الظاهرة لتوجهت السياسة الأمريكية ـ ومن الأمثلة في ذلك ما حدث من اتحام الغرب

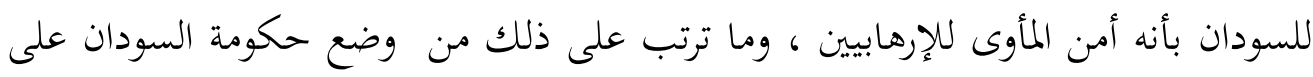

$$
\begin{aligned}
& \text { (1) الخطر الإسلامي بين الوهم والواقع،(90). } \\
& \text { (r)(الخطر الإسلامي بين الوهم والواقع،(r)(T). }
\end{aligned}
$$

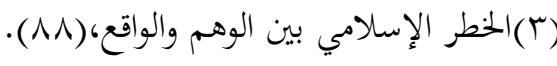


لائحة الدول الإرهابية ، وفرض العقوبات الإقتصادية عليها ، ثم يقول اسبيزيتو:"مع هذا لم

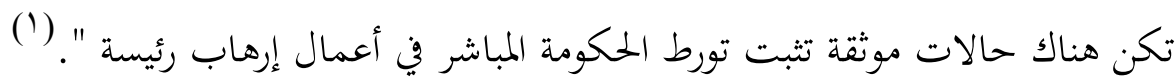

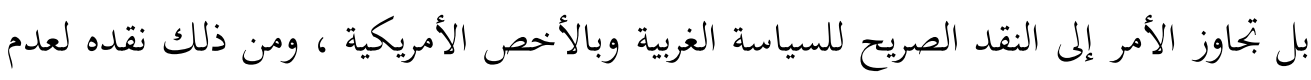

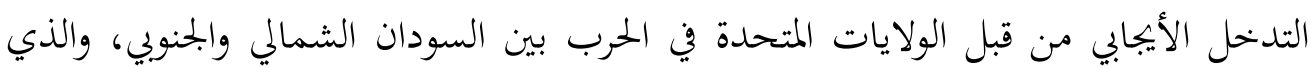

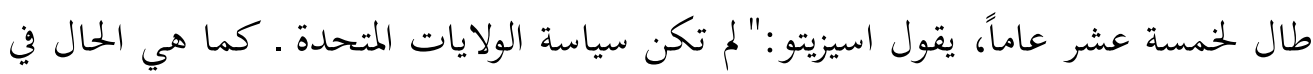

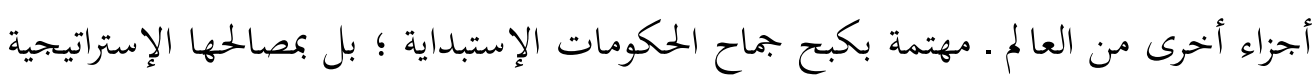

ذاها". (اجناء آحرى)

حسن التدرج التاريخي والعرض لتاريخ الدول والحركات والشخصيات ، مع عدم اغفال

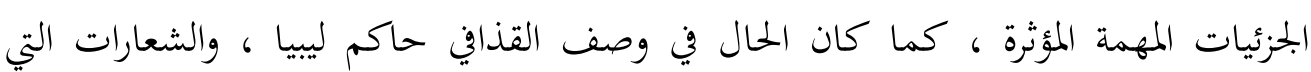

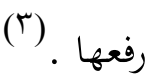

الدقة في الوصف المؤثر للشخصيات والأحداث ، ومن أمثلة ذلك ما قاله عند حديثه عن

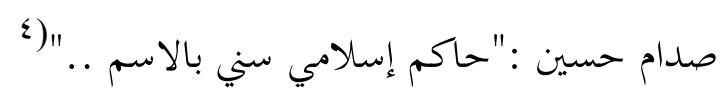

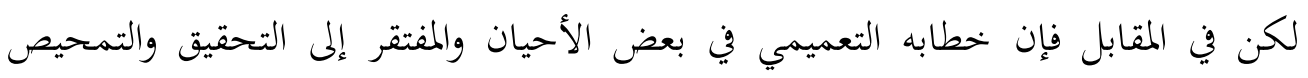

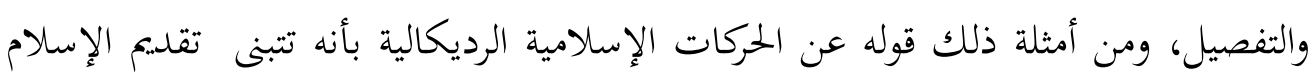

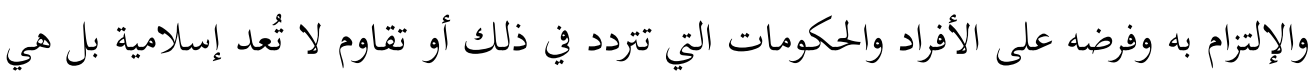

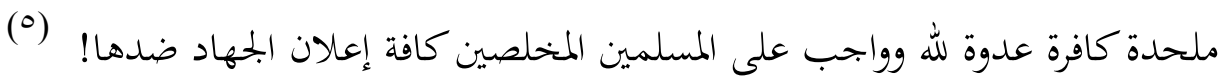

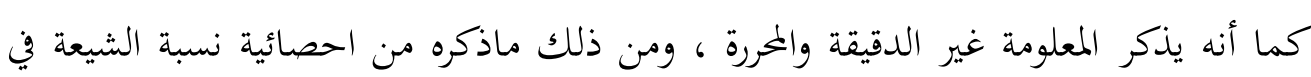

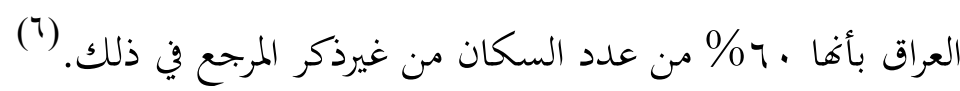

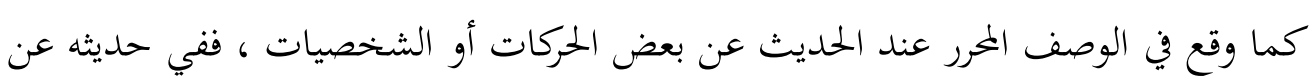

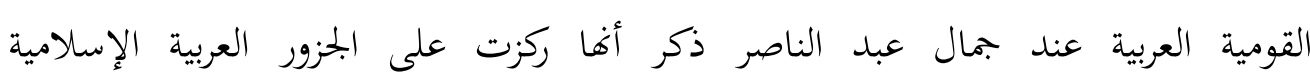

الأصيلة!!(')

$$
\begin{aligned}
& \text { (1) (1) (1) الخطر الإسلامي بين الوهم والواقع،(1) (1). } \\
& \text { (r) (1) الخطر الإسلامي بين الوهم والواقع،(110). }
\end{aligned}
$$

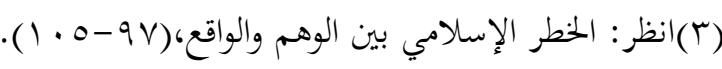

$$
\begin{aligned}
& \text { (؟) (الخطر الإسلامي بين الوهم والواقع، (TV). }
\end{aligned}
$$

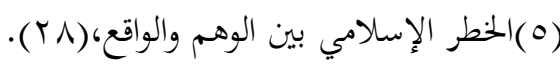

$$
\begin{aligned}
& \text { (T) (Tلخطر الإسلامي بين الوهم والواقع، (TV). }
\end{aligned}
$$




$$
\text { وتسمية الحبيب بورقيبة "المناضل العظيم"!(r) }
$$

مع عدم دقته عند الحديث عن بعض التصورات الشيعية ،والزعم بأفم عانوا من اضطهاد الحكام السنيين ، ووصفه للحسين رضي الله عنه بالإمام الشيعي، يقول اسبيزيتو:"إن المعاناة

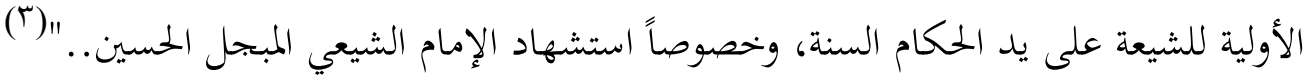
المبحث الثاني : كتاب "الحرب غير المقدسة الإرهاب باسم الإسلام" ، وفيه المطالب التالية:

المطلب الأول : الثعريف بالكتاب وعرض أهم الرؤى والأفكار:

الحرب غير المقدسة الإرهاب باسم الإسلام لمؤلفه جون اسبيزتو ،وترجمه مصطفى عبدالرزاق ،صدرت الطبعة الأولى المترجمة عامج . . بام ، عن دار الحوار للنشر والتوزيع، ويقع الكتاب في ع 9 | صفحة. يتمثل الهدف الرئيسي من وراء هذا الكتاب في شرح الكاتب وتفسيره للدافع وراء ارتكاب هجمات الحادي عشر من سبتمبر ووضعها في سياقها الأوسع.

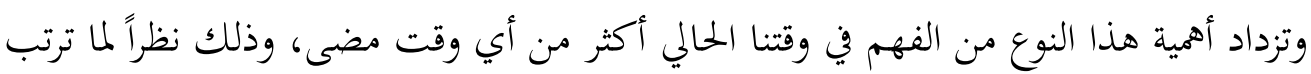
على أحداث الحادي عشر من سبتمبر من نتائج تمثلت في: استمرار تمديد خطر الإرهاب، وشن

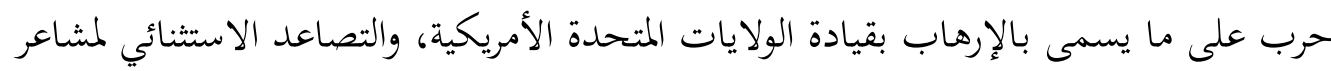
العداء والكراهية لأمريكا على مستوى العالم.

ويهتم هذا الكتاب بدراسة السياق التاريخي للشخصيات و الحركات الإسلامية والتي كان لها

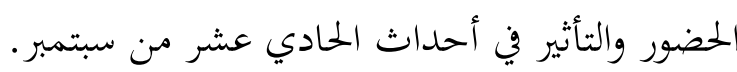
والكتاب نشر في بداية الحرب الأمريكية وقبل الحرب على العراق ،ويكتوي الكتاب على مقدمة وأربعة فصول وهي : الفصل الأول:صناعة الإرهابيين الجدد . الفصل الثاني: الجهاد والصراع من أجل الإسلام . الفصل الثالث: جيوش الله.

$$
\begin{aligned}
& \text { (1) الخطر الإسلامي بين الوهم والواقع،(ع).). } \\
& \text { (r) الخطر الإسلامي بين الوهم والواقع،(r)( ). } \\
& \text { (r)انظر :الخطر الإسلامي بين الوهم والواقع،(• (1) ). }
\end{aligned}
$$




$$
\text { الفصل الرابع: إلى أين نذهب من هنا؟ }
$$

في المقدمة يبدأ المؤلف بسؤال بعد كبير بعد سنين من النهاء مناء عقد كامل من اخهيار الإتحاد السوفيتي

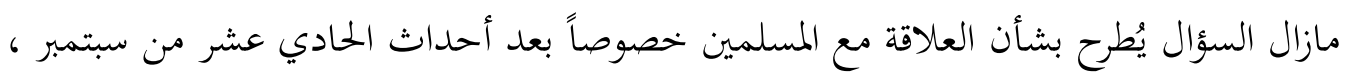

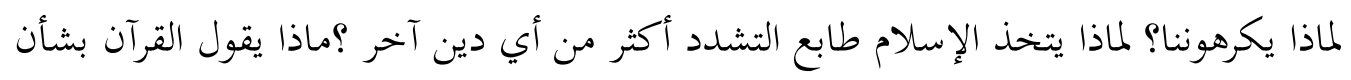

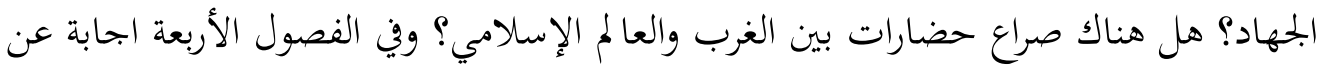

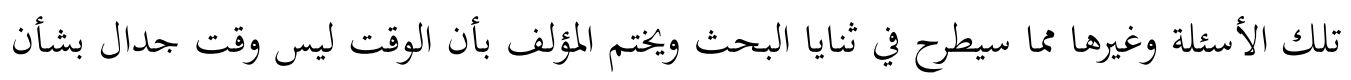
صراع الحضارات ، ولكنه وقت التلاحم العالمي وبناء جسور التفاهم والتعايش.

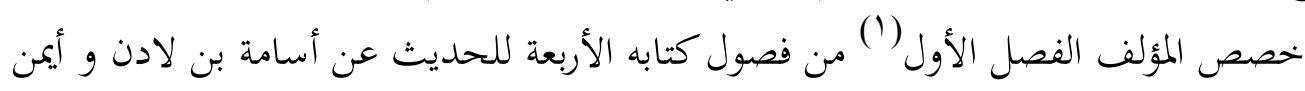

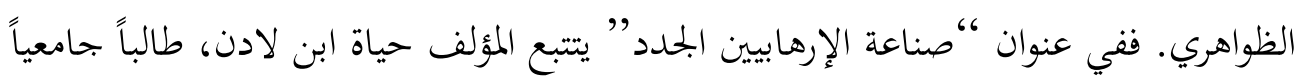

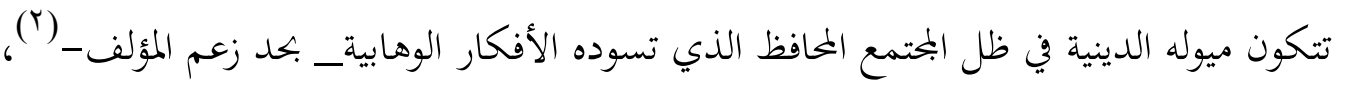
ومتى بدأت ملامح الفكر الجهادي في التشكل لديه في تلك المرحلة.

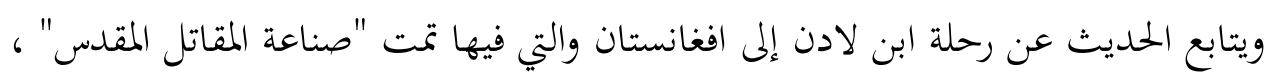

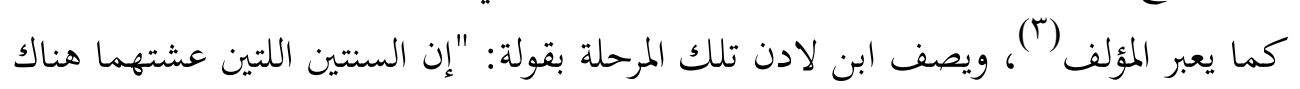

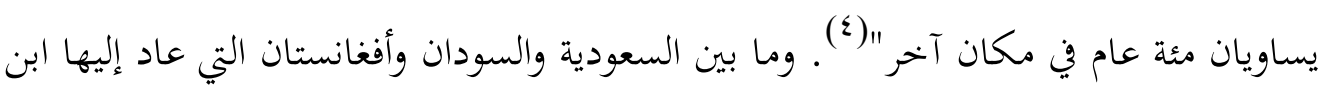

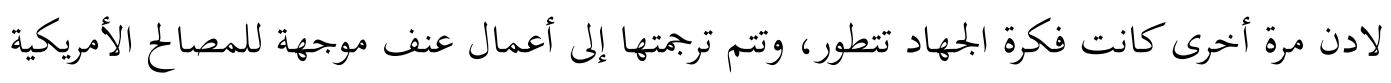

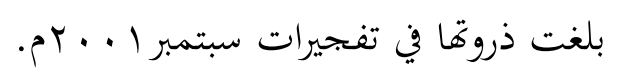

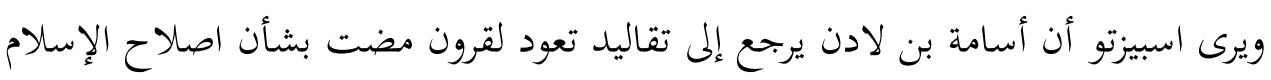

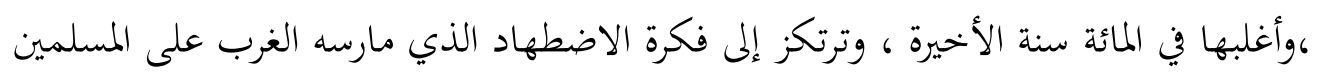
والإسلام (0)

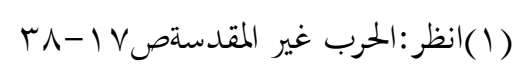

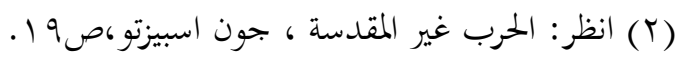

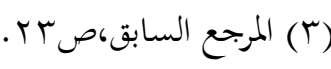

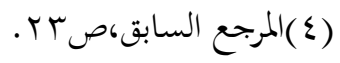

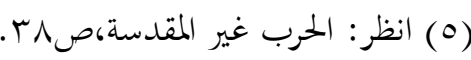


ولم تكن أفكار ابن لادن حول “"الجهاد الدفاعي"”(') حسب التعبير الذي يختاره مؤلف

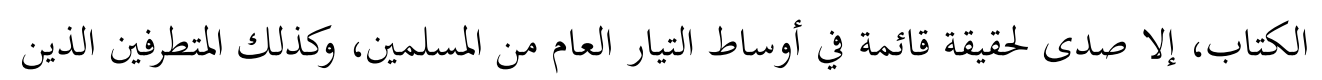
يعيشون في العالم الإسلامي (؟).

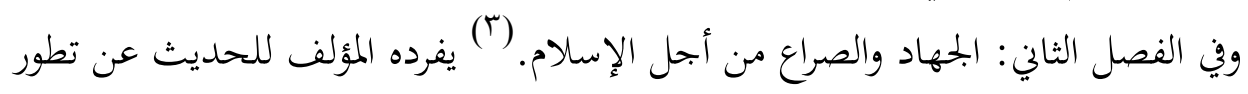

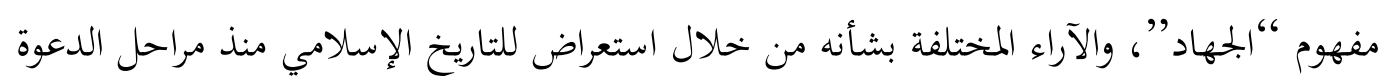

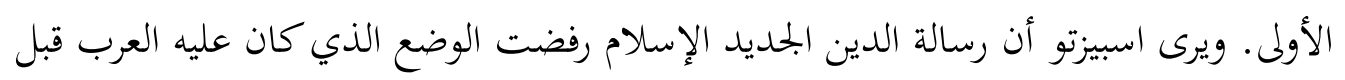

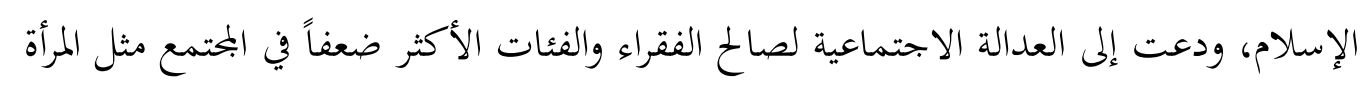

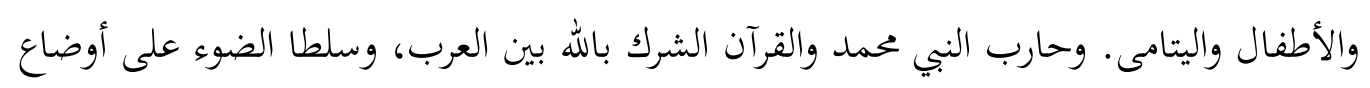

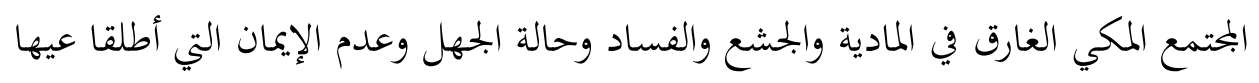

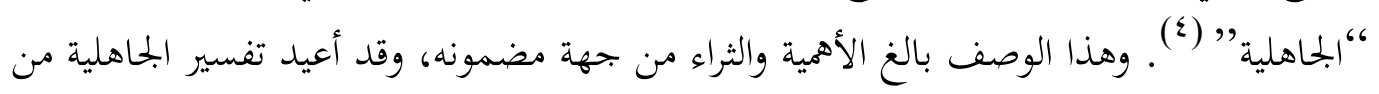
قبل الأصوليين اليوم لوصف البمتمع الغربي وإدانته. يقول المؤلف :"لقد حثت دعوة محمد الناس على الكفاح والجهاد من أجل إصلاح بحتمعاقم إلدانه

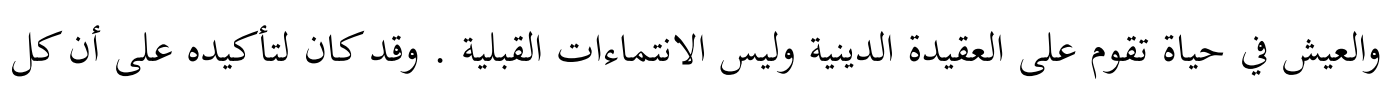

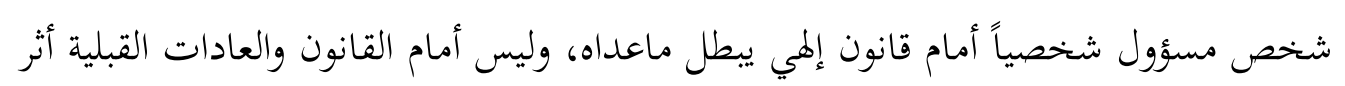
الصدمة على مختلف أسس المجتمع العربي"(ن).

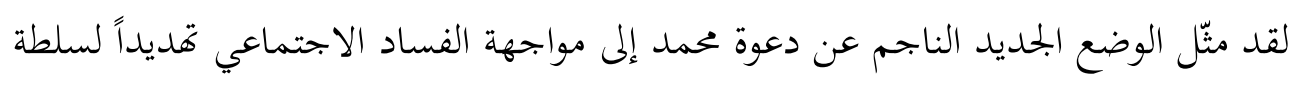

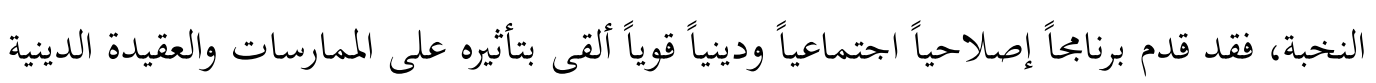

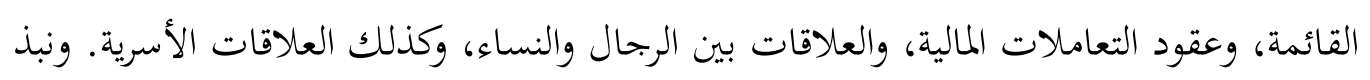

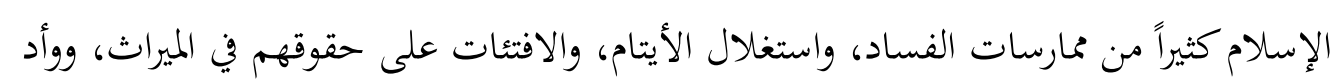

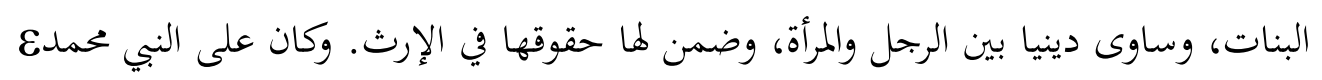

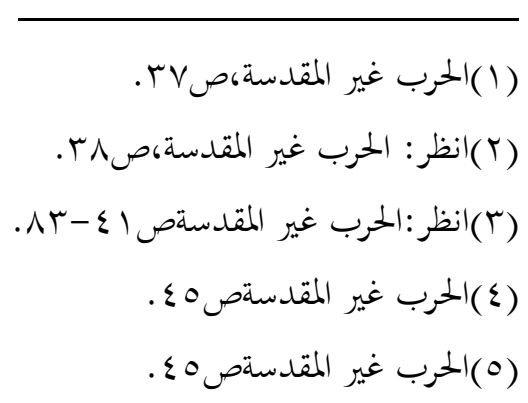


وصحابتها خوض معارك صعبة وإعلان الجهاد لتعزيز مواقفهم ومواجهة التحديات التي فرضت

في ظل هذه النظرة إلى الإسلام، باعتباره ثورة اجتماعية وإصلاحية ذات طابع روحي وتقدمي، يقدم المؤلف مقاربته للتاريخ والفكر الإسلامي وموقع الجهاد منهما. وهو يعبر في كل الأحوال عن معرفة واسعة وشاملة، وقدرة على التقاط الخيوط والخطوط الأساسية التي تبلورت معها فكرة الجهاد الإسلامي بالصورة التي ظهرت عليها لدى الجماعات المتطرفة. وبالقدر نفسه تبدو المتابعة الجيدة والمعرفة الدقيقة بالعالم العربي والإسلامي، بأطرافه المترامية، في العصر الحديث، ودقائق تاريخه السياسي والاجتماعي، والإشكاليات الحضارية والمعرفية التي واجهها خلال قرنين من الزمان.

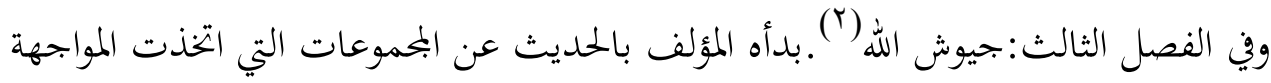
المسلحة أسلوباً للتغيير من جهيمان في واقعة الحرم إلى ابن لادن في أحداث الستمبر ، ويعرج الحديث بذكر الإستعمار وأثره على نفوس المسلمين في العصر الحاضر ، وحال الدول الإسلامية الحديثة موقفها من الحداثة الغربية من باكستان حتى الجزائر، وموقف الحكومات من الحركات الجهادية ، كما كان الأمر في مصر مع الجماعة الإسلامية وغيرها ،وفلسطين مع حماس والجهاد ،والجزائر مع جبهة الإنقاذ ، وتحت عنوان التهديد الوهابي ، يتحدث فيه عن أثر الإسلام الوهابي أو

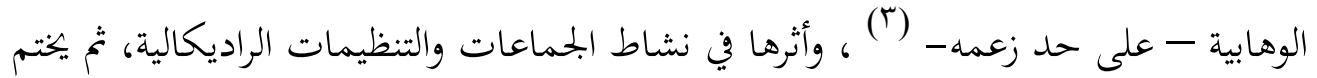
اسبيزتو بقوله" لقد مر " جنود الله " عبر عدة مراحل حتى أصبحوا أكثر عالمية مما هو متصور، وقد ركزت معظم الجماعات على أقطارها، وتمثلت بشكل أساسي على أقطارها وتمثلت بشكل رئيسي في الحركات المصرية ، الجزائرية ،التونسية ،فيما شكل الجهاد الأفغاني ضد الاحتلال السوفيتي نقطة تحول تمثلت في سفر المسلمين بأعداد كبيرة إلى أفغانستان للالتحاق بعمليات الجهاد ضد اضطهاد المسلمين..... ليس فقط للدفاع عن المسلمين ضد الاضطهاد وإنما للإطاحة بالقوى العالمية التي

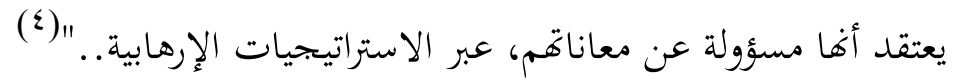


وفي الفصل الرابع :أين نذهب من هنا؟ يؤكد المؤلف أن من المشكلات الأساسية في تعامل الغرب الفاب

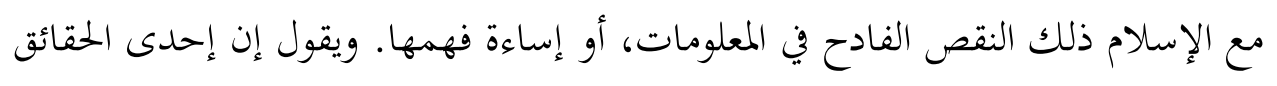

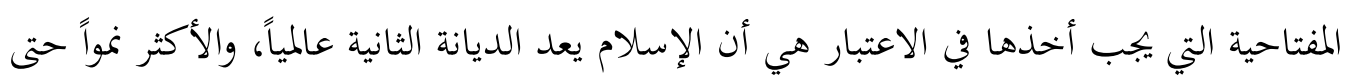

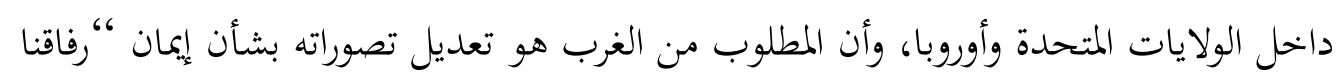

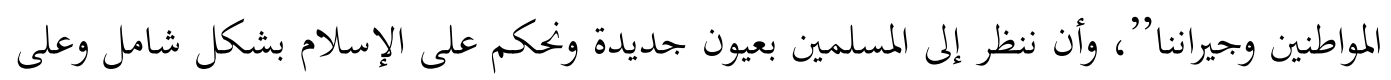

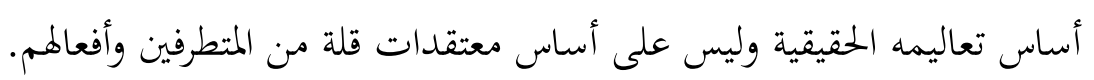

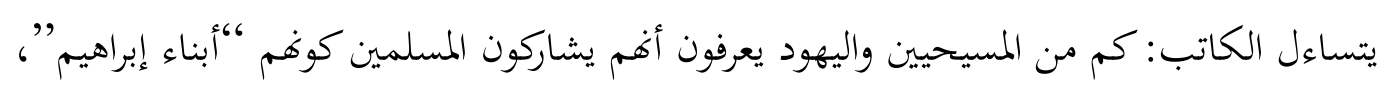

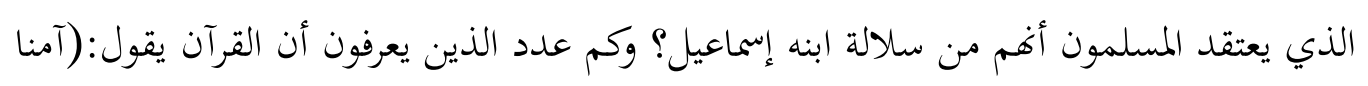

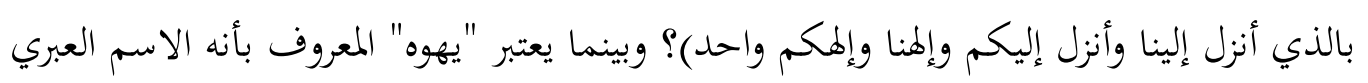

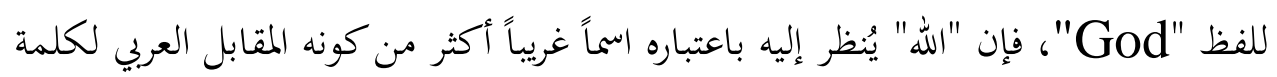

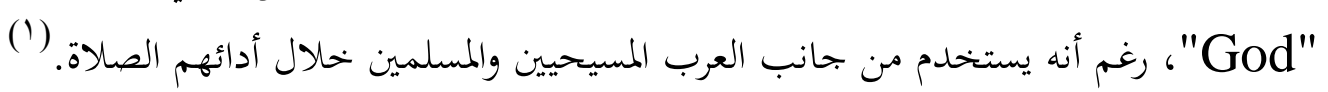

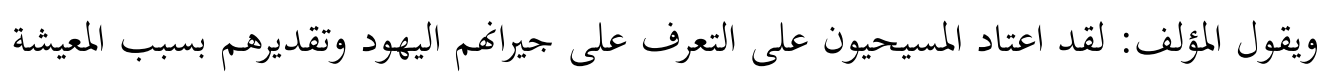

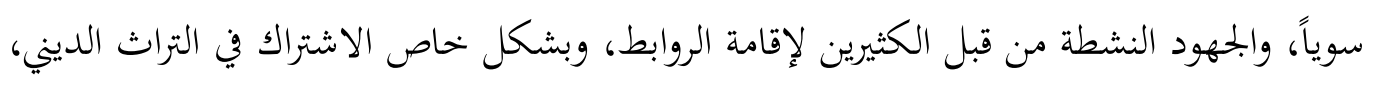

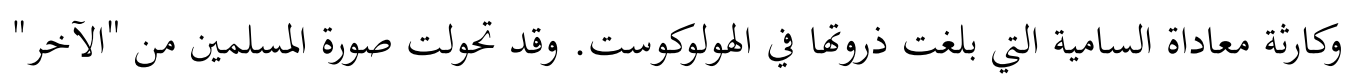

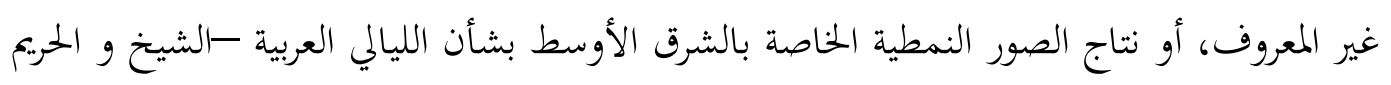

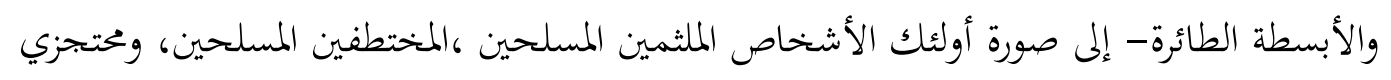

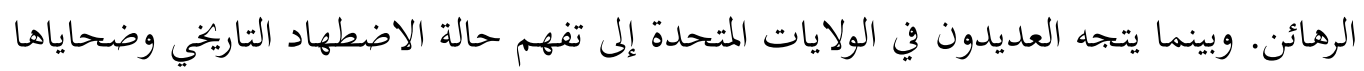

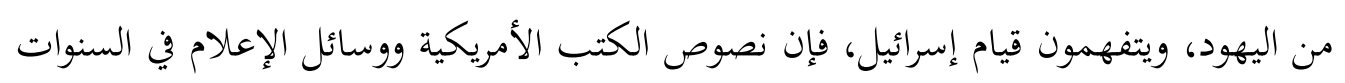

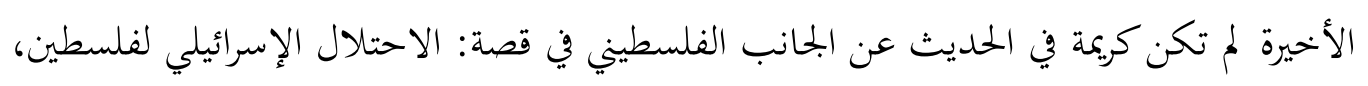

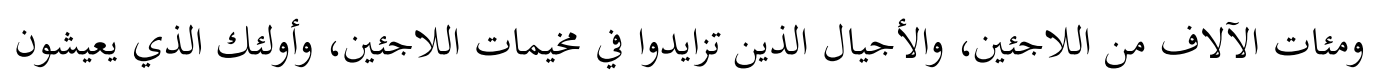

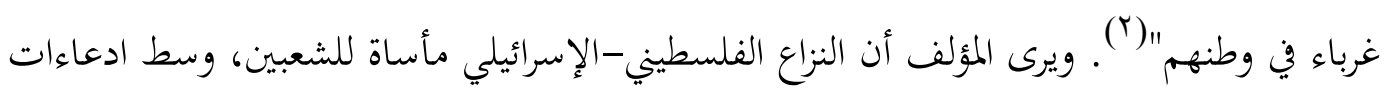

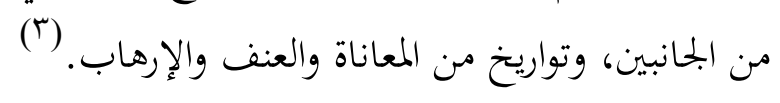


ويختم المؤلف بذكر أمثلة لشخصيات اسلامية كانت مثالاً واقعياً في محاولة التعايش مع الغرب ،

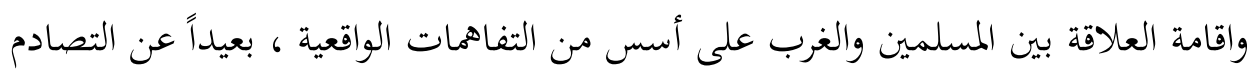

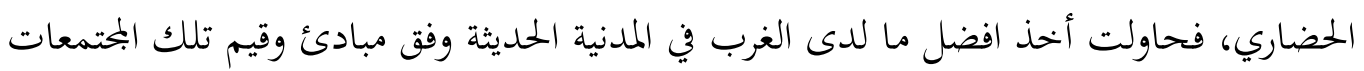

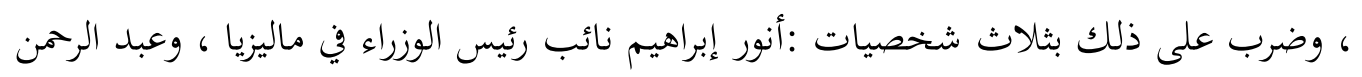
واحد رئيس إندونيسيا ، ومحمد خاتمي رئيس ايران.

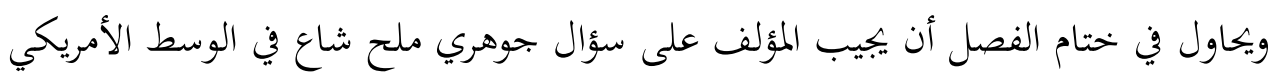

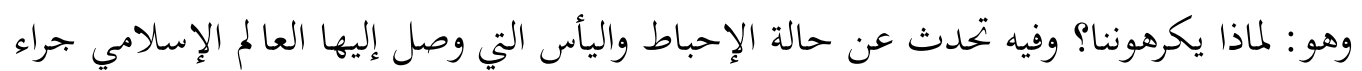

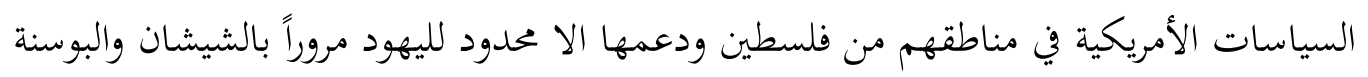

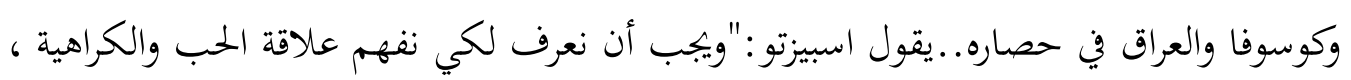

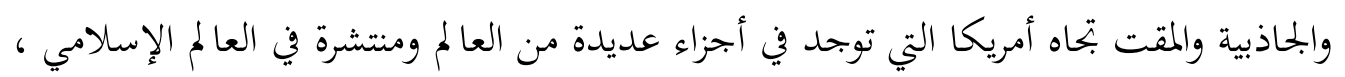

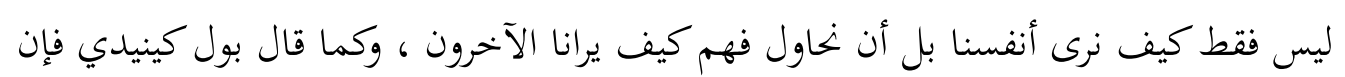
قليلين منا يسألون:

كيف نبدوا لهم ، وماذا يمكن أن تكون أوضاعنا إذا كانت الأمور على عكس ماهي عليه الآن

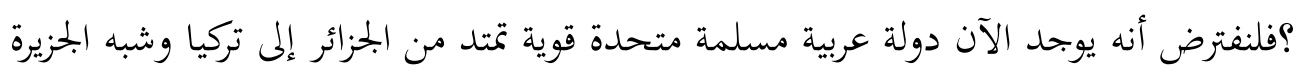

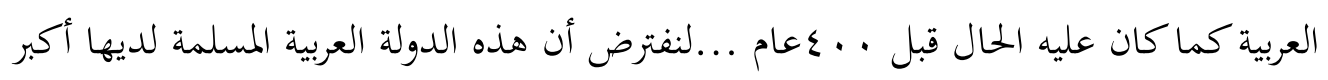

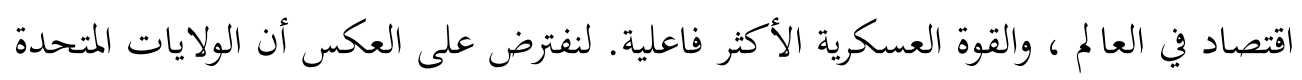

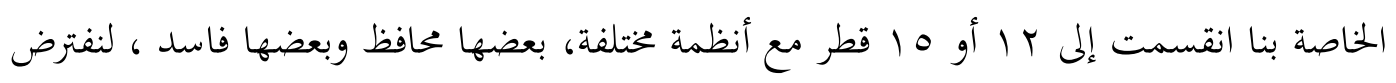

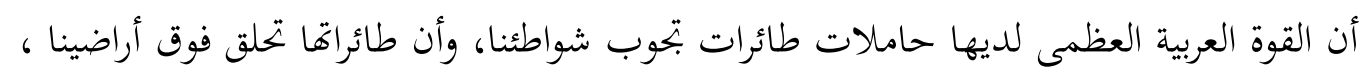

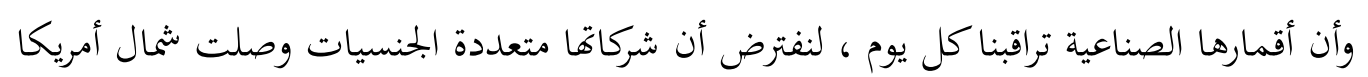

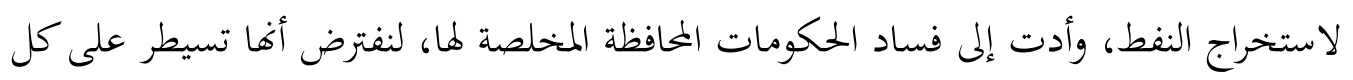

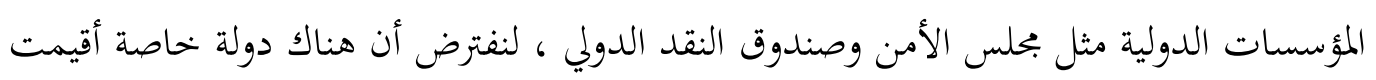
في شمال أمريكا منذ خمسين عام مضت ، من دين مختلف ولغة مختلفة عنا وأن الدولة العربية

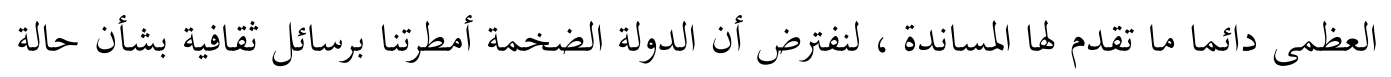

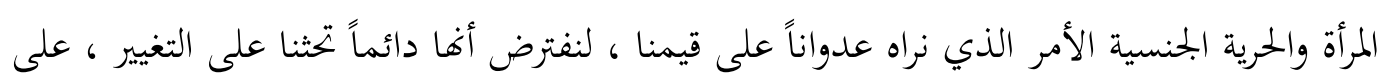

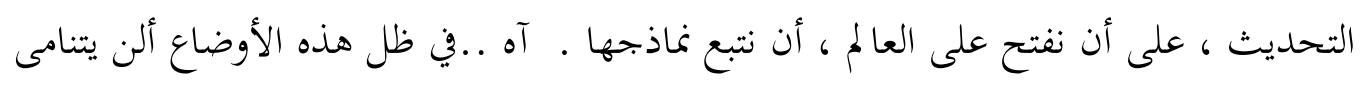


بدى العديد من الأمريكيين حالة البغض بتحاه هذه الدولة الضخمة ، ويتمنون أن يلحقون بها شئياً

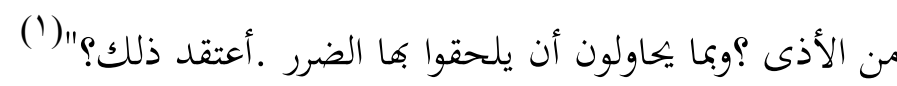
إن التفاهم والتفهم لواقع المسلمين اليوم هما جوهر ما يحرص عليه اسبيزتو في مؤلفاته السابقة

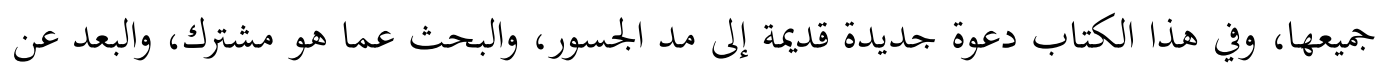
فلسفة صراع الحضارات ،لصالح الجميع. المطلب الثاني: المنهج المتبع في الكتاب:

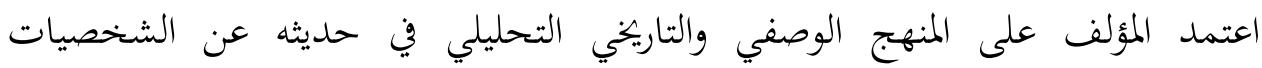

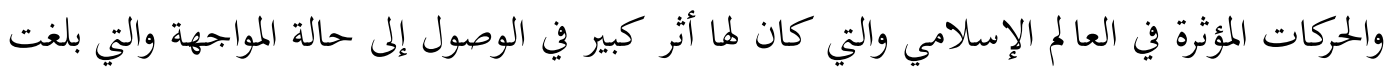

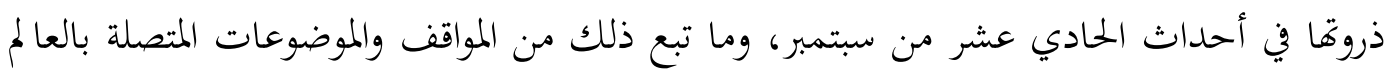

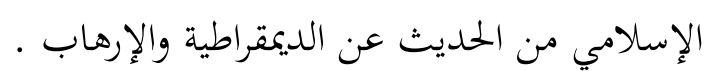

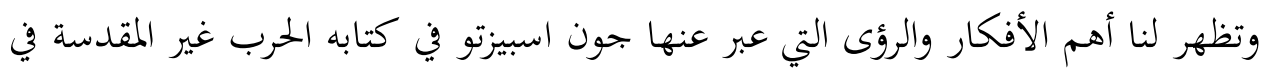

يرى اسبيزتو أن أسامة بن لادن اعتمد على التراث الإسلامي الذي جاء به ابن

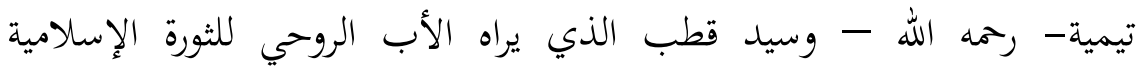

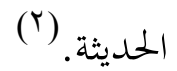

ويرى اسبيزتو أن الإشكال الذي حصل لدى المسلمين في مفهوم الجهاد

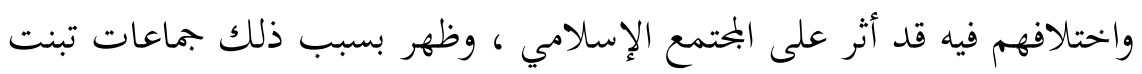

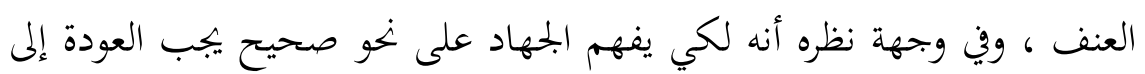

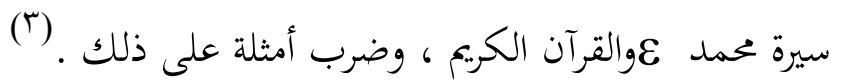

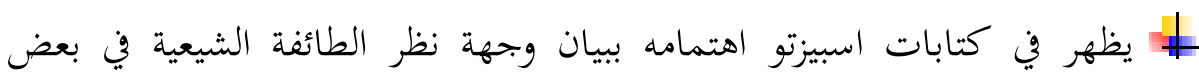

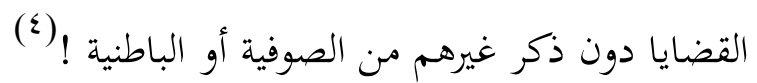


ويشير المؤلف إلى أن كثيرين في الغرب لم يكونوا يعرفون شيئاً عن الإسلام مع أنه

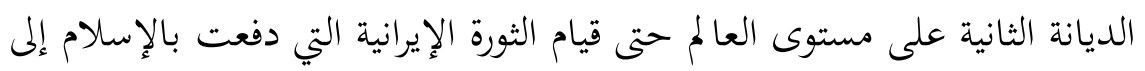
بؤرة الاهتمام العالمي! ويرى أن مما يثير السخرية أن الصدام المعاصر للغرب مع الإسلام بدأ من الأعمال

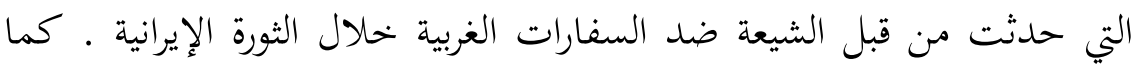

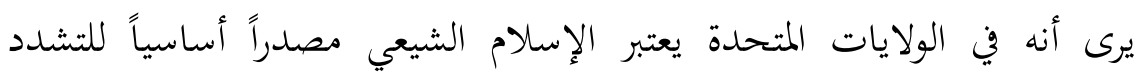

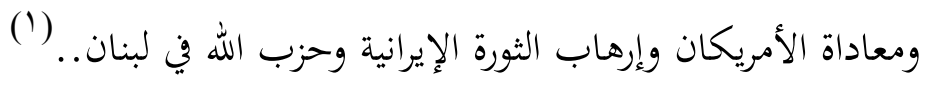

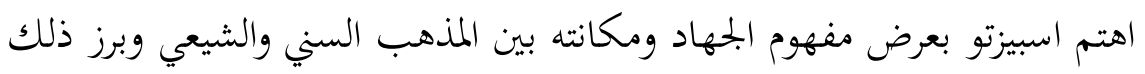

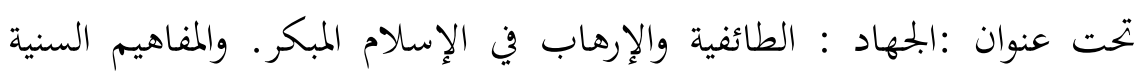

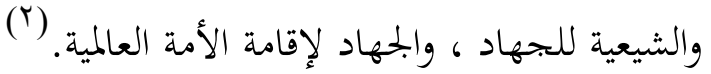

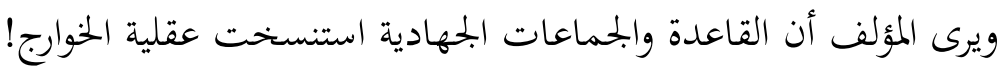

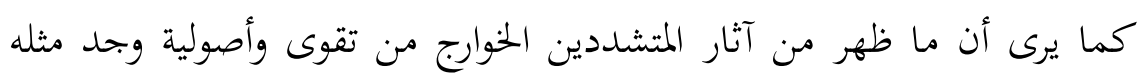

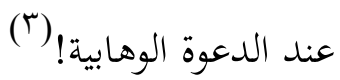

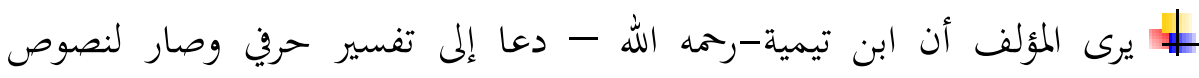

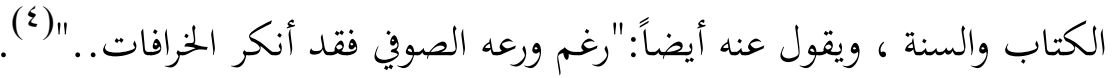

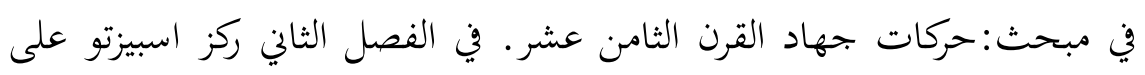

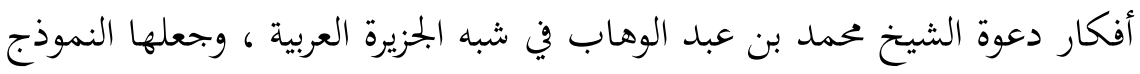

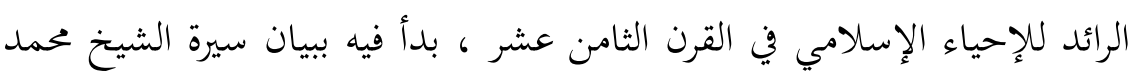
بن عبد الوهاب وابرز اهتماماته ودعوته. (o)

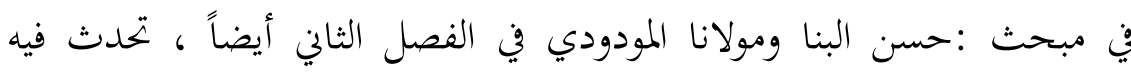

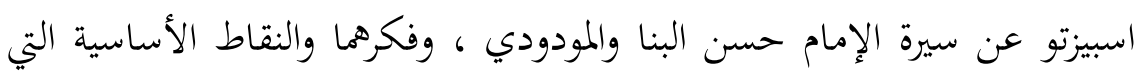

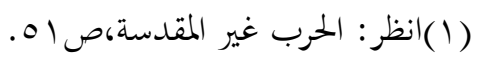

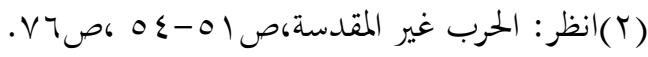

$$
\begin{aligned}
& \text { (r)|نظر : الحرب غير المقدسة، }
\end{aligned}
$$

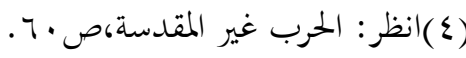

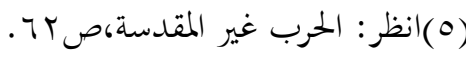


أشتركا فيها ، ويرى أغما أكدا على شمولية الإسلام وانطلقا من تفسير جديد

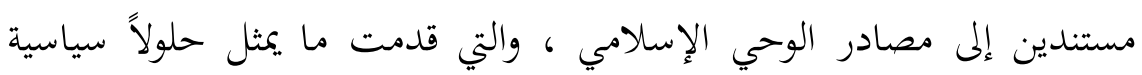
وثقافية واقتصادية لتحديات العصر. (1) ويرى أن كلاٍ من حسن البنا والمودودي ركز على التنديد بالاستعمار والتهديد لتحديد

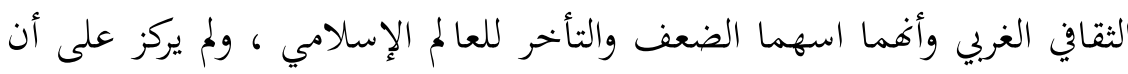

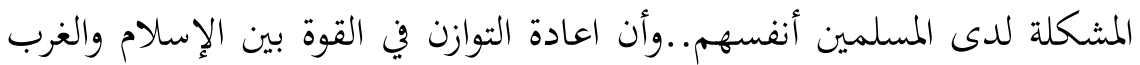

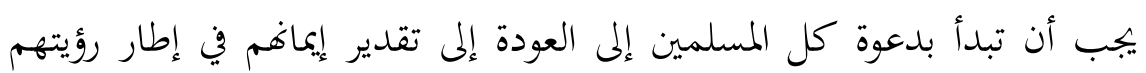
الكلية. (ان) وتحت عنوان : سيد قطب "الأب الروحي وشهيد الراديكالية الإسلامية"يرى

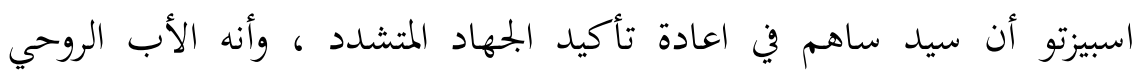
للمتطرفين المسلمين حول العالم. (َ) اهتم المؤلف بعرض فكر الشيعة مقارنة بعقيدة أهل السنة في كثير من المواضع

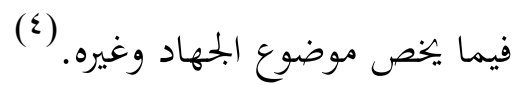
ويرى اسبيزتو أن هناك أربعة ردود أقعال من قبل المسلمين للإستعمار تشكل

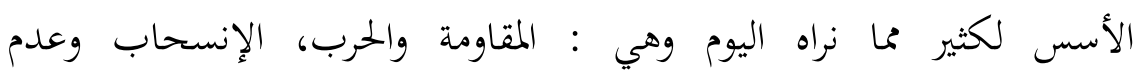

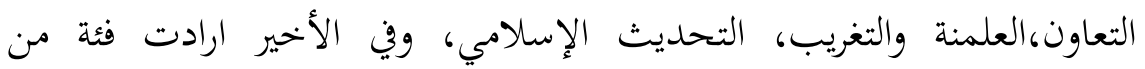
الإسلاميين مد جسور إلى الثقافة الغربية والإستفادة منها في أعظم ما وصلت إليه

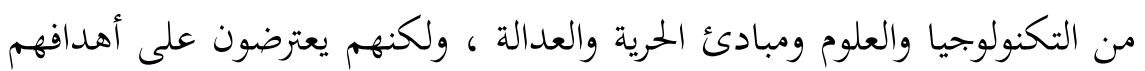

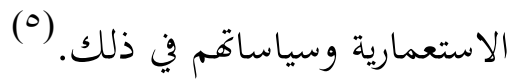
يرى اسبيزتو أن الوهابية توصيف للتوجهات المسرفة في المحافظة ، والتي تتمثل

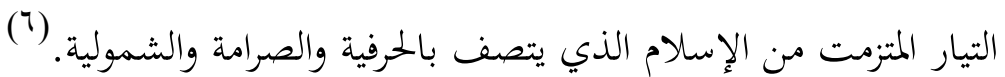

$$
\begin{aligned}
& \text { (1) (انظر: الحرب غير المقدسة، (باصT. }
\end{aligned}
$$

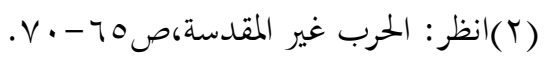

$$
\begin{aligned}
& \text { V(r)|نظر: الحرب غير المقدسة، •V. }
\end{aligned}
$$

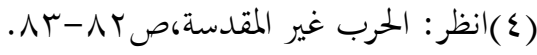

$$
\begin{aligned}
& \text { (0)|نظر : الحرب غير المقدسة، وبح-9 } 9
\end{aligned}
$$

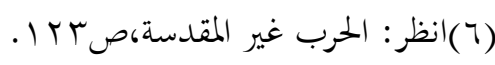


ويعترف اسبيزتو بقلة معرفة الغرب عن الإسلام وأصوله ، كما ينبه على تفهم الغرب قيام اسرائيل بينما يغضون الطرف عن قصة الاحتلال الإسرائيلي

(1) (فلسطين.

ويرى الؤلف أنه يلزم في الحكم على الأعمال الإرهابية اجتناب الحكىم على الإسلام من خلال معايير مزدوجة ، فيقول:"فعندما نقترب من اليهودية والمسيحية أو نفهم معتقداتنا ....6 فإننا نتعامل بشكل مختلف، فنحن نفسر العنف والقتل والاستعمار باسم اليهودية والمسيحية من خلال مصطلحات العصور وسياقاتها ، أو ندين مثل هذه الأفعال ونصفها بالضلال أو التطرف ..."دون نسبة شيء من

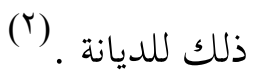
ويرى اسبيزتو أن الإسلام كان أكثر تسامحاً ، ووفر حرية دينية أكبر لليهود والمسيحيين المحليين ،وقضى على اضطهاد الهراطقة والذي شهدته المسيحية(r). ويبن خطأ السؤال :هل كان الإسلام متوافقاً مع الحضارة الغربية؟ لأنه يتجاهل التداخلات في الماضي والحاضر ، ويضع الحضارة الغربية في مرتبة متقدمة باعتبارها

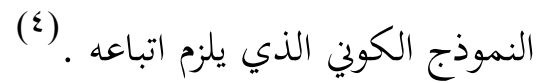

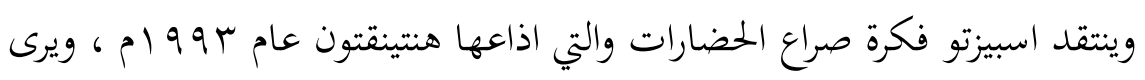
أهفا كانت الإجابة السهلة لأسباب أحداث الحادي عشر من سبتمبر ، وكانت من ابرز جوانب انتقاده لمنتيقتون اعتباره الحدود الإسلامية دموية بل بتحاوز ذلك لتشمل الإسلام نفسه إذ يقول هنتينقتون:"إن المشكلة الأساسية بالنسبة للغرب

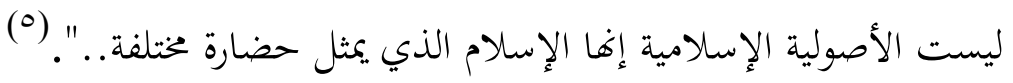

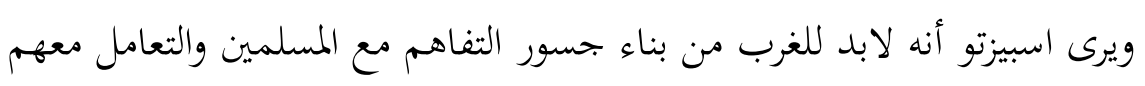

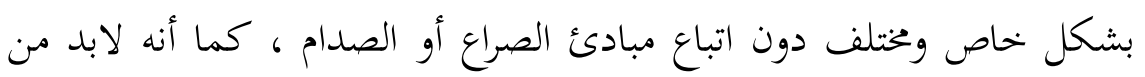

$$
\begin{aligned}
& \text { (1) (1نظر: الحرب غير المقدسةصمى اص. }
\end{aligned}
$$

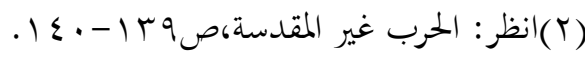

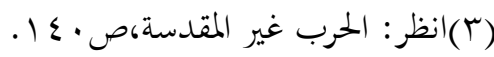

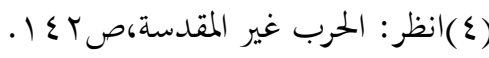

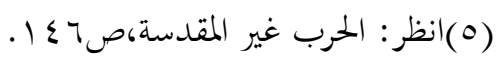


معالجة شاملة لما يسمى بظاهرة الإرهاب لا تعتمد فقط على القوة العسكرية بل

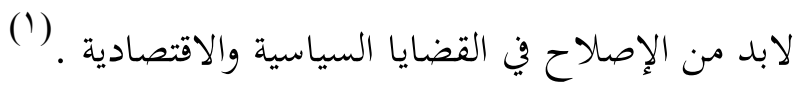

المطلب الثالث: نظرة جون اسبيزتو للثقافة الإسلامية من خلال كتابه الحرب غير

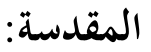

ظهر اسلوب طرح التساؤلات والأسئلة اسلوب ظاهر وجميل في كتب اسبيزتو، وفيه تشويق لمعرفة الأجابات ، والتي يتبعها اسبيزتو بعد اجابته عن سؤال بسؤال جديد ، من أمثلة ذلك : لماذا يكرهوننا؟ لماذا يتخذ الإسلام الطابع المتشدد أكثر من أي دين آخر؟هل هناك صراع حضارات بين الغرب والعالم الإسلامي؟أليس من الأهمية البالغة الآن أكثر من

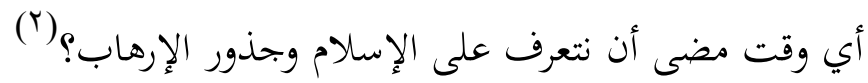

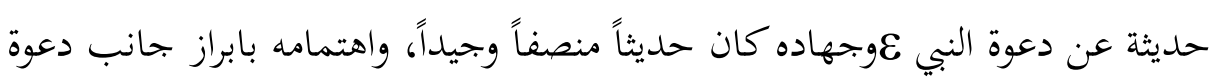
النبي علنبذ حمية الجحاهلية ،واعطاء الأيتام والنساء حقوقهم،وتحريم قتل المرأة والأطفال والنساك في الجهاد الإسلامي.... (T) استدلاله بالآيات القرآنية في اثبات والمساندة لما يقوله ، فالكتاب ألفه للمسلمين وغيرهم

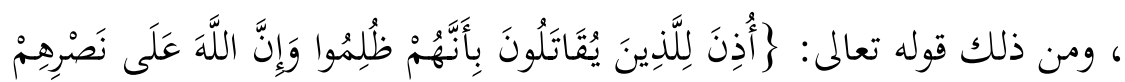

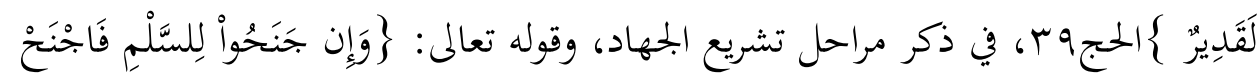

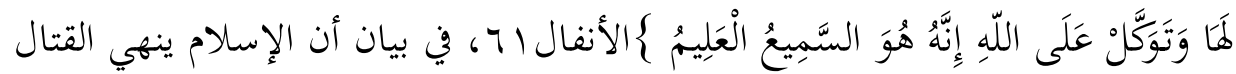

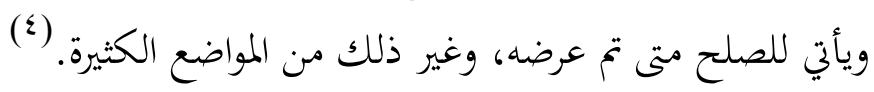
إلقاؤه التبعية على السياسة الأمريكية في ظهور حركات التطرف في العالم الإسلامي ، يقول اسبيزتو :"إن قصة مصر كحليف للولايات المتحدة تعد واحدة من أكثر الأمثلة بشأن كيف يمكن للأوضاع السياسية والاقتصادية بحتمعين مع القمع أن يتسببا في إيجاد حركات 
معارضة عسكرية تسيء استخدام الإسلام من أجل توسيع التحريض واضفاء شرعية على الى

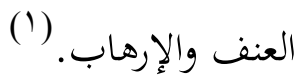

|اعتذاره لعمليات حماس وأها بسبب حالة اليأس والظلم الفلسطيني ، يقول اسبيزتو :"فلا

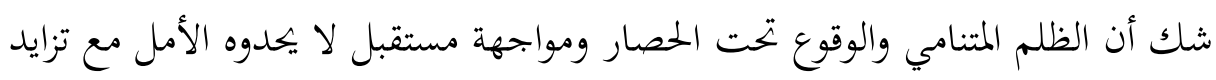

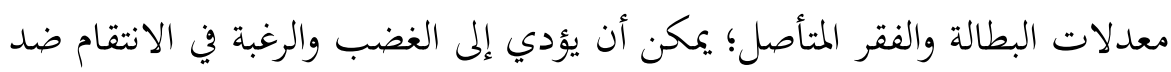

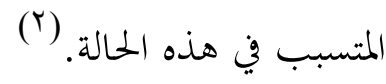

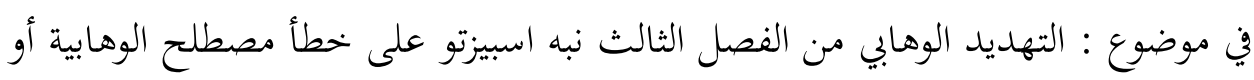

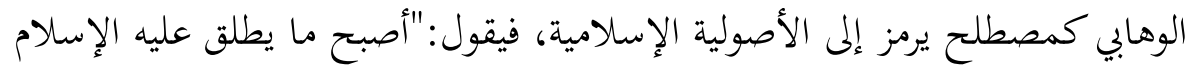

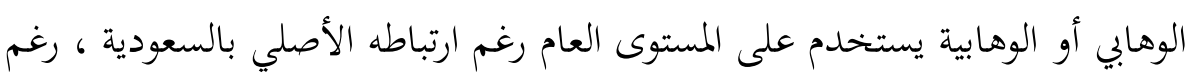

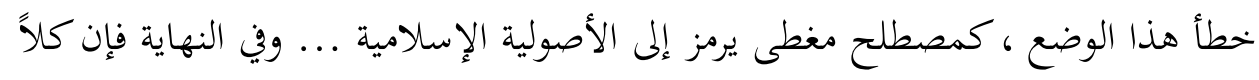

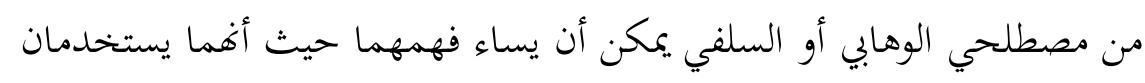

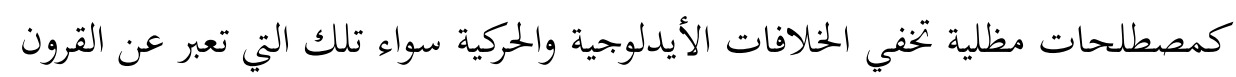

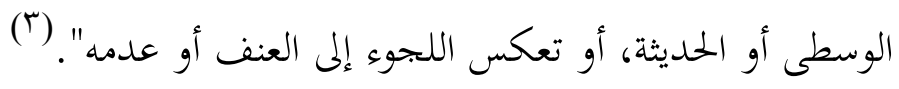

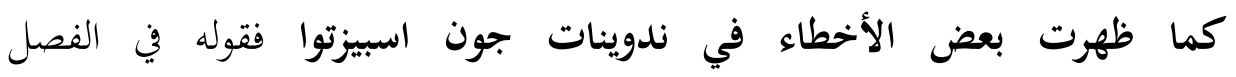

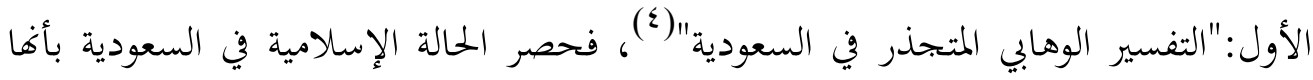

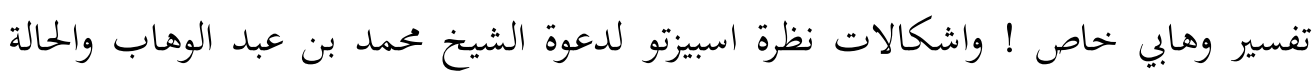

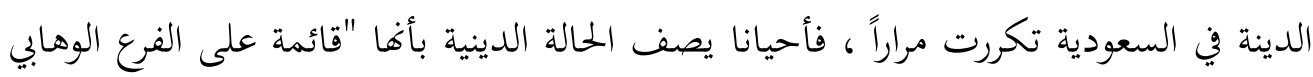

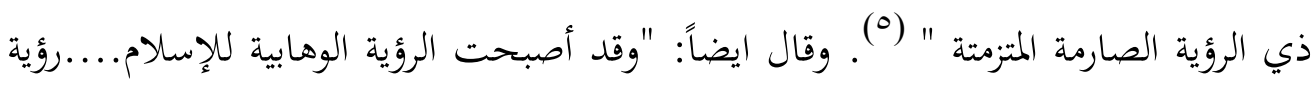

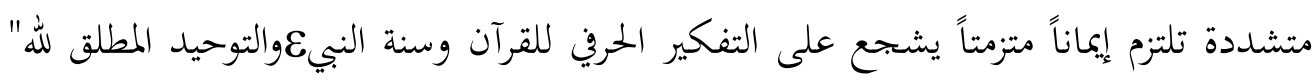

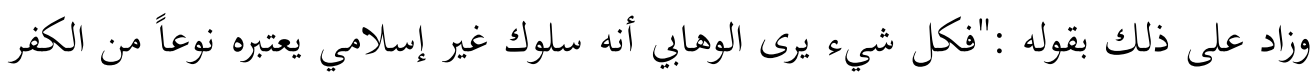

(1) الحرب غير المقدسة، • 11.

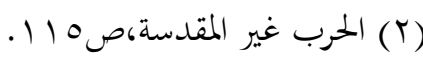

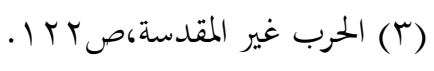

(ع) الحرب غير المقدسة ،صو 19.

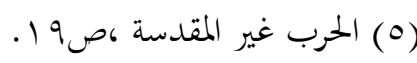


يجب أن يتم مواجهته بالجهاد.."(')، ولا شك أن في ذلك تحني يكشفة النتاج العلمي لأئمة

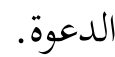
بل ذهب إلى أكثر من ذلك في النظرة التي تحيط بها التهم عن الدعوة النجدية فيقول عن حركة

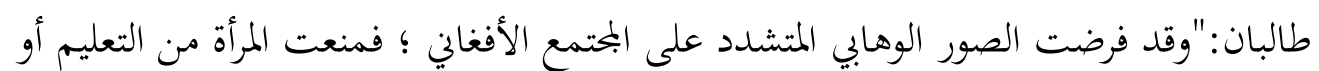

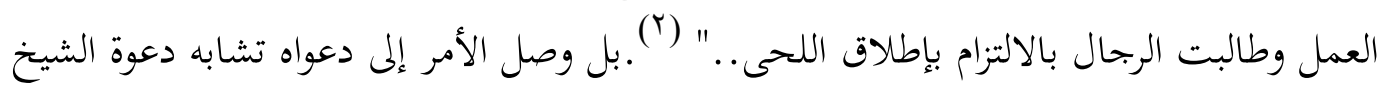

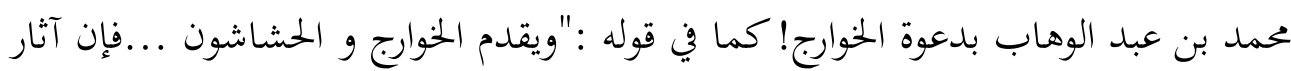

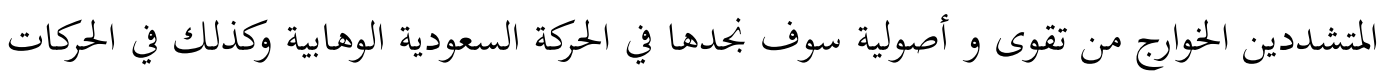

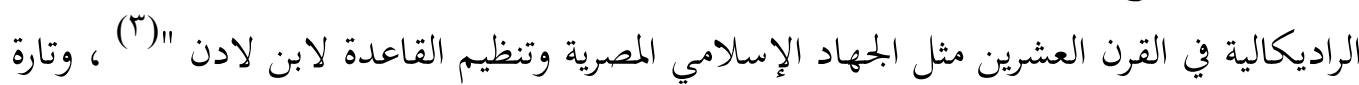

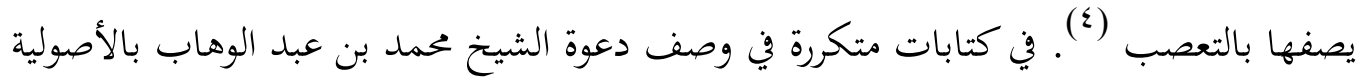

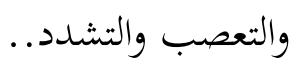

|| حديثه عن أن الجيوش الإسلامية يحركها للجهاد العائد الاقتصادي الناجم عن الغزو..

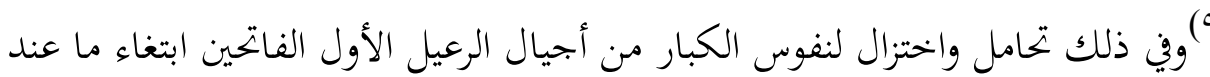

$$
\text { الله ونشراً لدينه. }
$$

بحث اسبيزتو الإشكالات في مفهوم الجهاد وتعدد ذلك(") ، مع أن الإشكال في تطبيقات

$$
\text { تطبيقات الجهاد أما مفهومه فواضح. }
$$

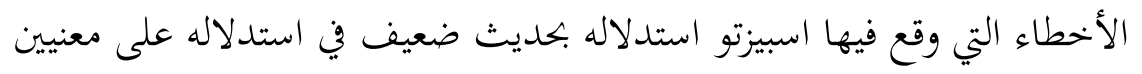

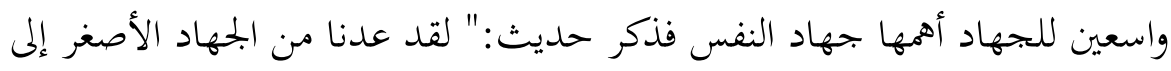

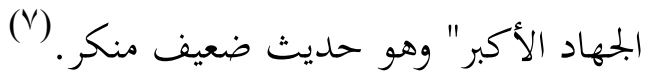

$$
\begin{aligned}
& \text { (1) الحرب غير المقدسة ،ص. ب. }
\end{aligned}
$$

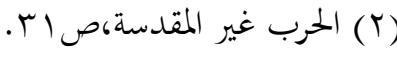

$$
\begin{aligned}
& \text { (T) الحرب غير المقدسة ،صله ه، وانظر صفحة آجا. }
\end{aligned}
$$

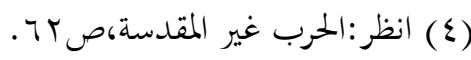

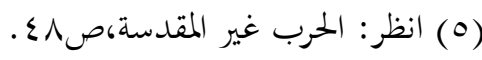

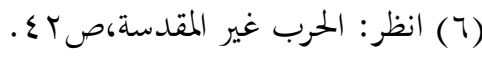

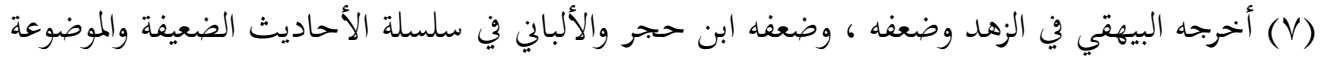

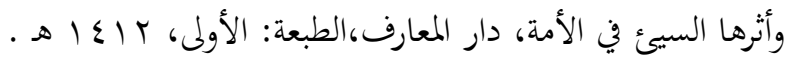


في حديثه عن سيد قطب قال عنه : "قائد الجناح العسكري للإخوان"(') ولا شك أن

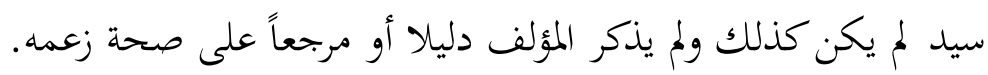

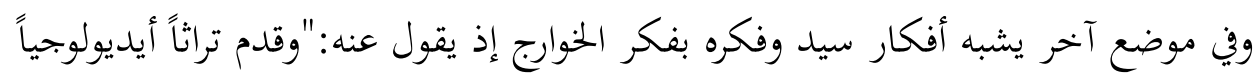

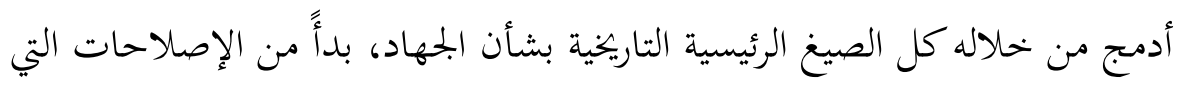

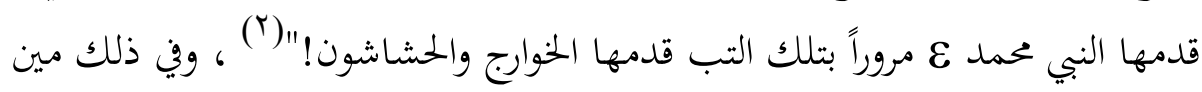
وميل عن الحق واضح في بيان فكر سيد . وصفه عن الشيخ ابن باز - رحمه الله - بالتطرف ، فيقول عنه: "كان معروفاً بأنه غزير

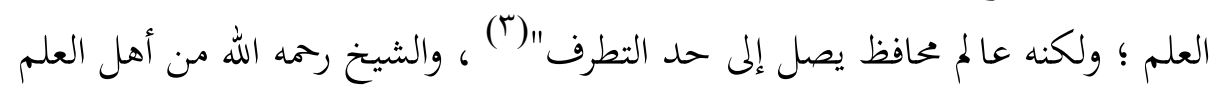

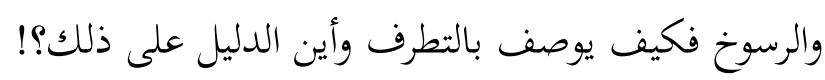

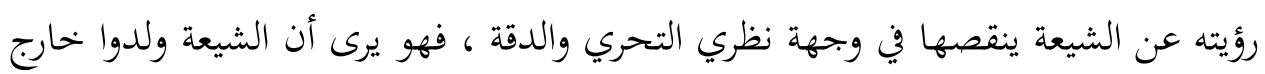

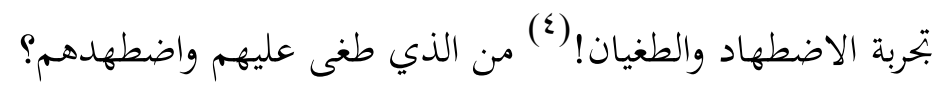

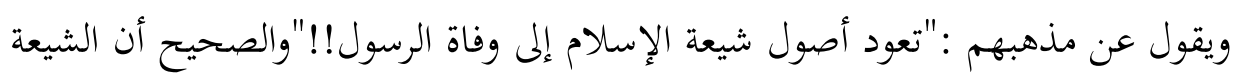

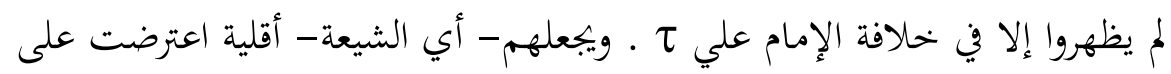

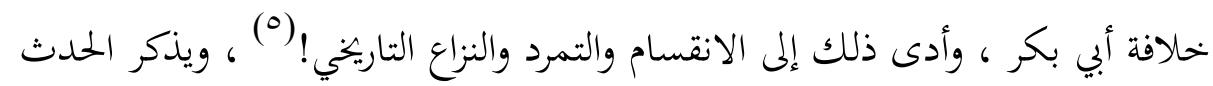

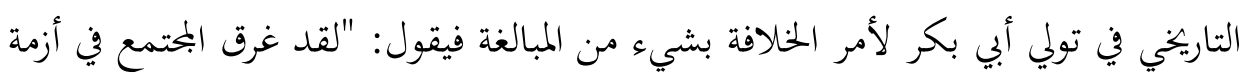

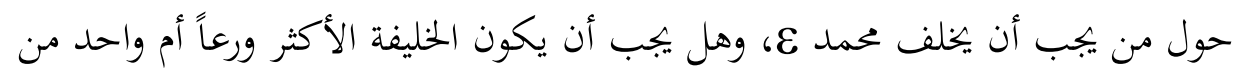

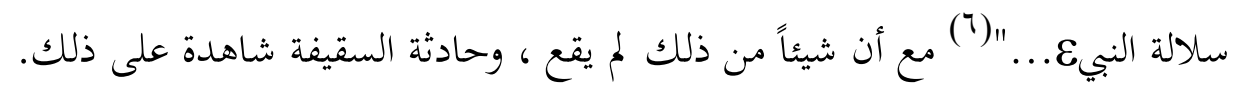

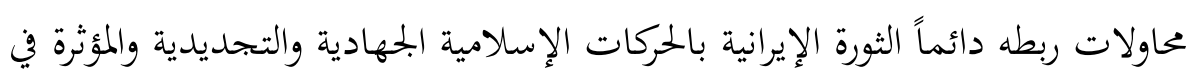
(v) العالم الإسلامي التورة

$$
\begin{aligned}
& \text { (1) الحرب غير المقدسة ،ص. r. }
\end{aligned}
$$

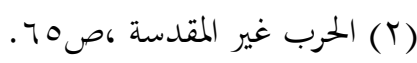

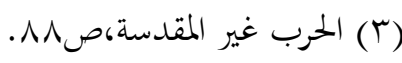

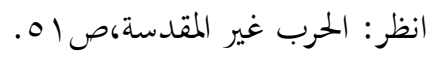

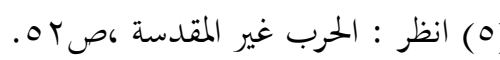

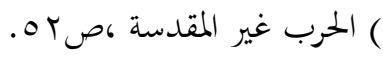

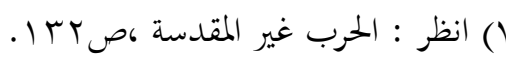


ولا يتوقف عن ذكر بحربة الدولة الإسلامية في إيران ، وأها مثال لإقامة دولة إسلامية

(') بصبغة دينية

ولاريب أن الثورة الإيرانية أعلنت أهما إسلامية إلا أها خالفت ذلك وصارت طائفية خاصة

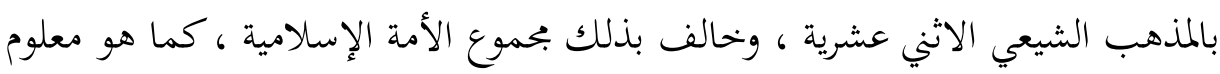
المبحث الأول : كتاب "من يتحدث باسم الإسلام" "كيف يفكر -حقاًأ- مليار مسلم؟"نتائج أكبر استطلاع عالمي حتى الآن .لمؤلفه جون اسبيزتو وداليا مجاهد، وفيه لإليه

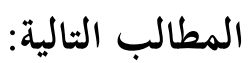

المطلب الأول : التعريف بالكتاب وعرض أهم الرؤى والأفكار:

من يتحدث باسم الإسلام؟ هذا هو السؤال الرئيس الذي يعرض له الكتاب، والإجابة كانت

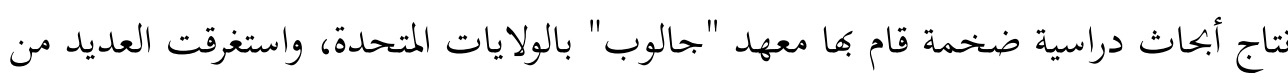

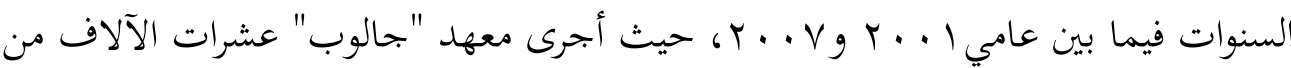

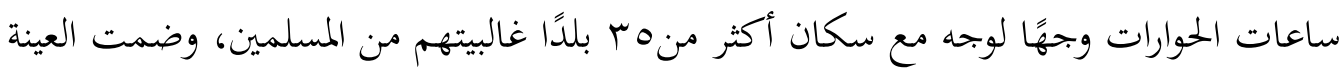

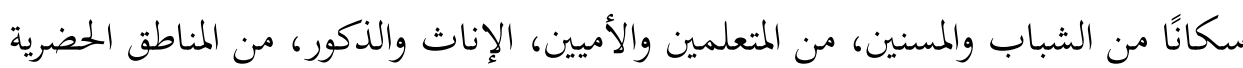
والريفية. (r)

ومؤلّفّا الكتاب هما جون اسبوزيتو، أستاذ الديانات والشؤون الدولية والدراسات الإسلامية

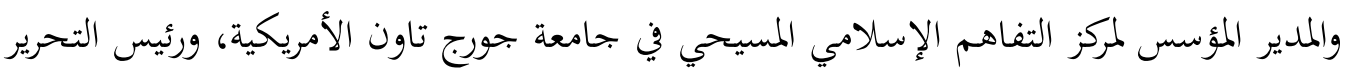

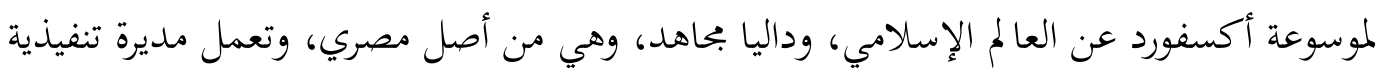

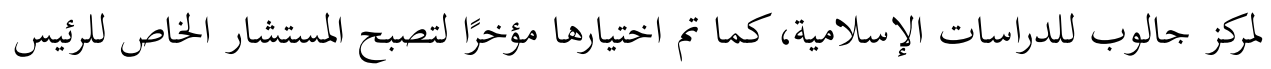
الأمريكي أوباما للشئون الإسلامية. وقام بترجمته إلى العربية الدكتور عزت شعلان، وصدر في القاهرة عن دار الشروق المصرية، وقدم للترجمة الكاتب فهمي هويدي. (َ)

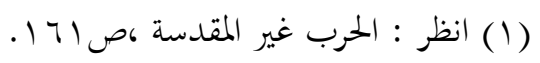

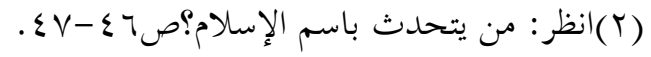

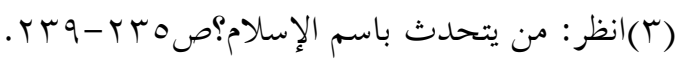


ومركز جالوب للدراسات الخاصة بالمسلمين، هو مركز بحثي لا ينتمي لأي من الأحزاب

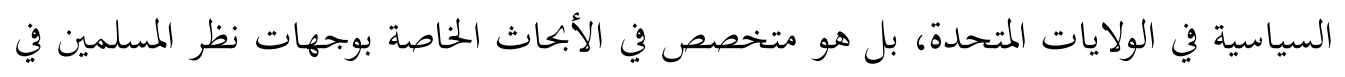

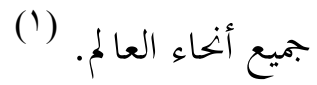
وبعدما تم بناء إطار متناسق من خلال التحليل والتدقيق للبيانات ، تولى تناول النطاق الثقافي له

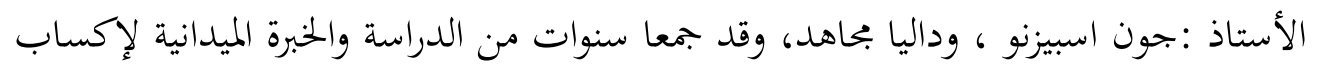

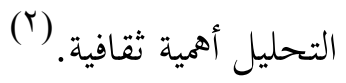

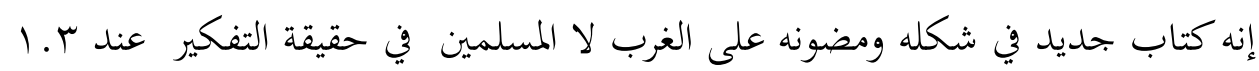

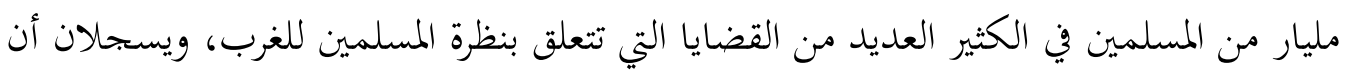

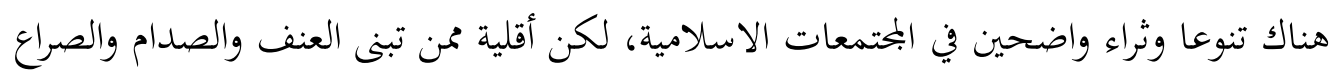

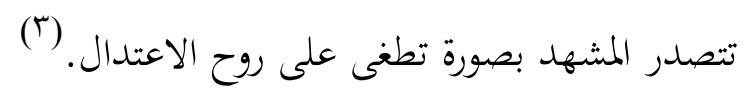

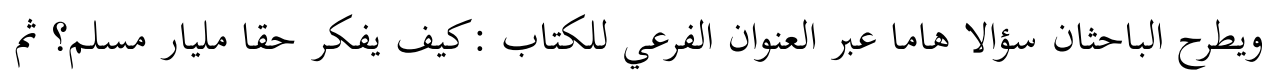

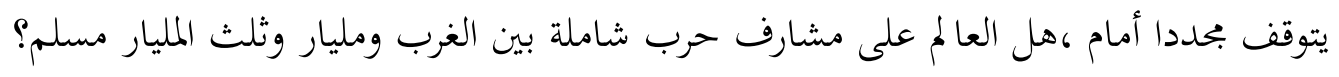
مؤكدا أنه عندما تبحث وسائل الإعلام عن إجابة على هذا السؤال، فإنها فن العادة تتجاهل العابل الآراء

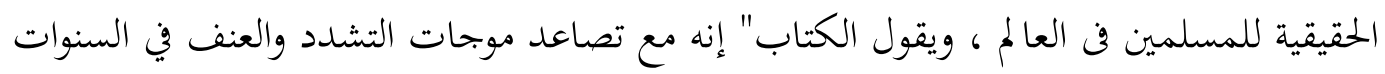

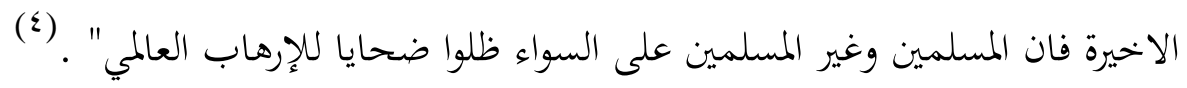

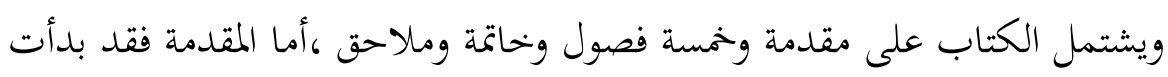

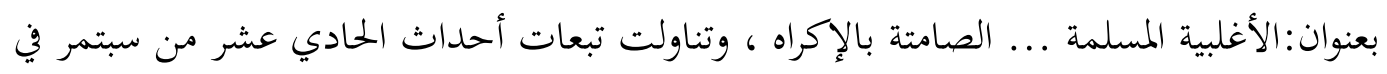

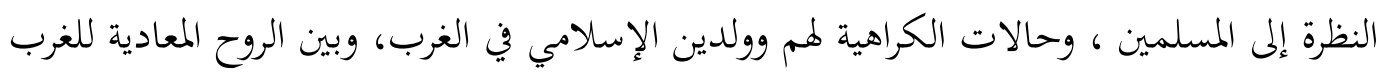

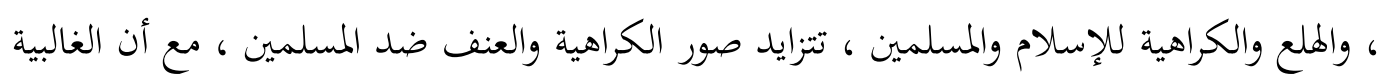

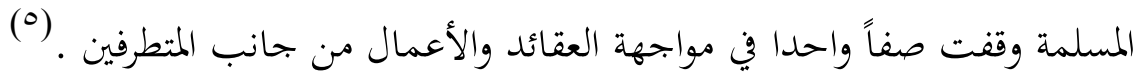

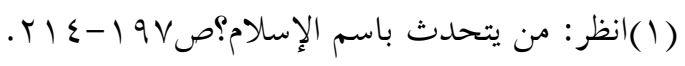

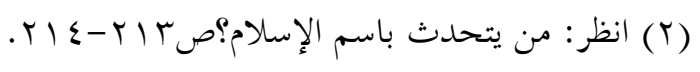

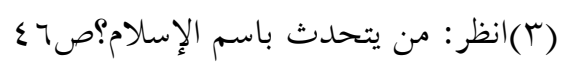

$$
\begin{aligned}
& \text { (ع)من يتحدث باسم الإسلام؟ص0 ؛ . }
\end{aligned}
$$

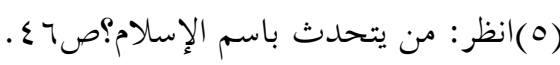


وتوضح المقدمة أن الدراسة تمت بالمسح على عينة تمثل أكثر من ـ 9\% من ؟ بـ ابليون مسلم في

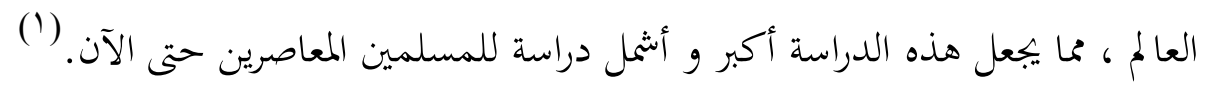

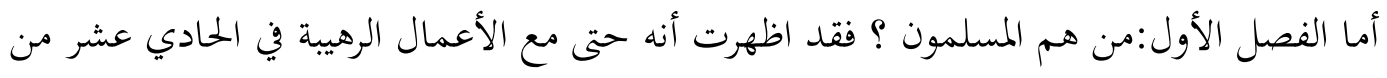

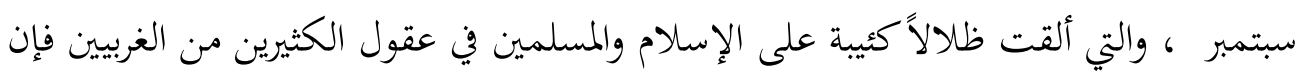

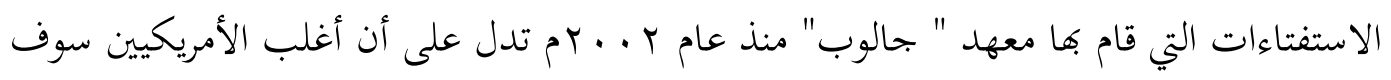

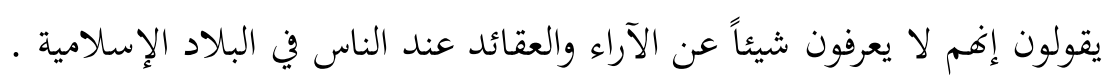
ويبحث في الإجابة عن أسئلة جوهرية :مالذي يعتقده المسلمون بتحاه أعمال العنف التي يواجده

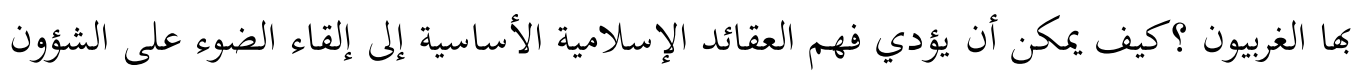
المعاصرة؟ وغيرها. (؟) وفي الفصل الثاني: الديمقراطية أو الثيوقراطية؟ تتابع الأسئلة عن موقف الإسلام ونظرة المسلمين

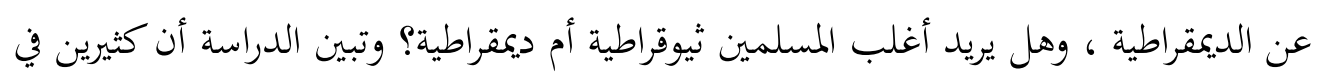

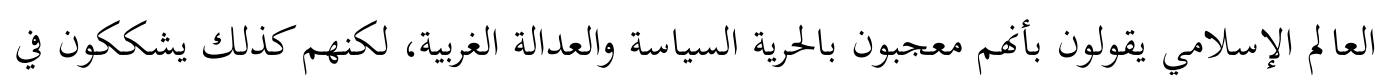

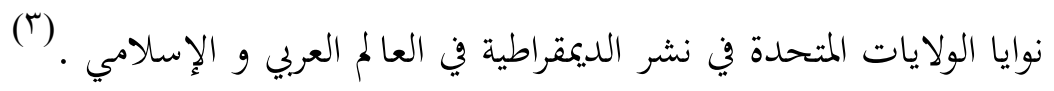

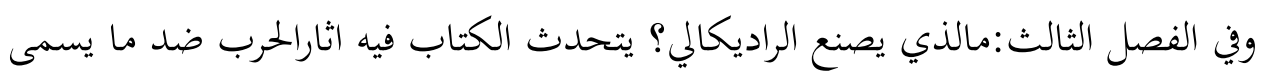

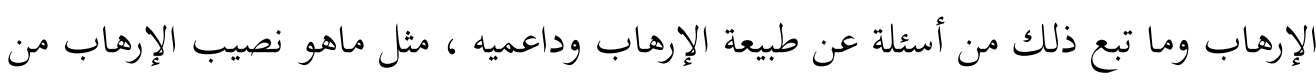

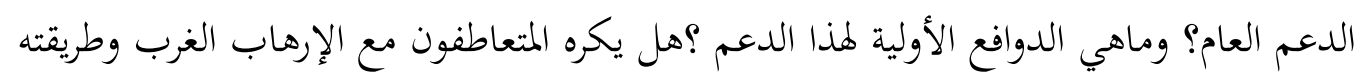

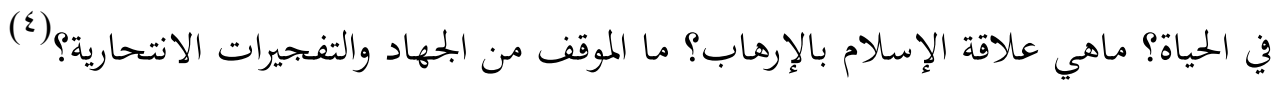

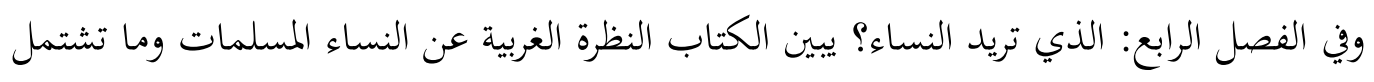

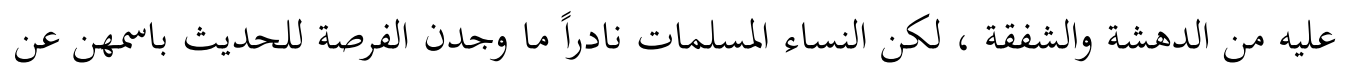

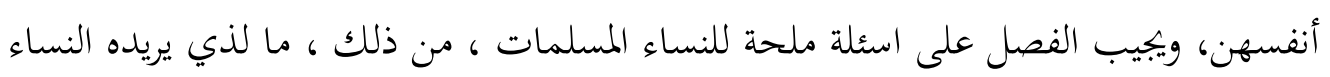

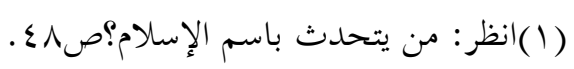

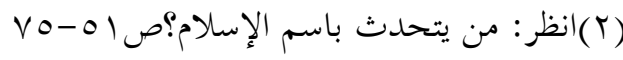

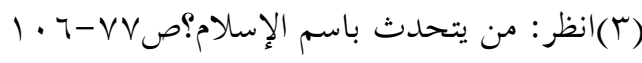

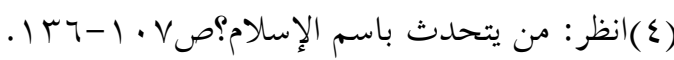


المسلمات حقاً؟ كيف ينظر إلى حقوقهن والدين والغرب؟ ما هي أفضل الطرق تأثيراً في الدعوة إلى تقوية النساء المسلمات؟ (1) وفي الفصل الخامس: صدام أم تعايش؟يبين الكتاب أن من الأمور الحاسمة في الحرب ضد الإرهاب ليس النصر والثفوق العسكري فحسب ، بل لابد من مشاركات ثقافية بين المُتمعات

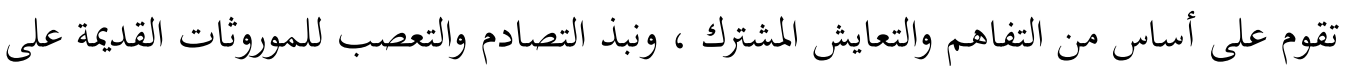

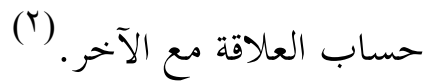
ثم الخاتمة والتي أكدت على العودة إلى مفهوم التعايش والتفاهمات المشتركة ، وأنه ليس من المحتوم أن

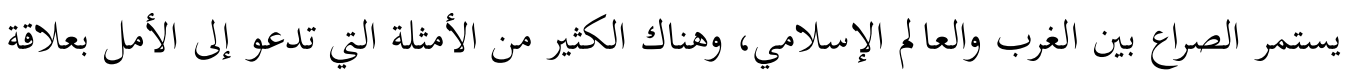
تفاهمية. (r)

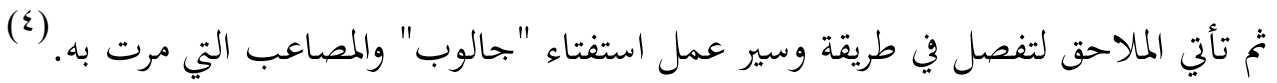
المطلب الثاني: المنهج المتبع في الكتاب:

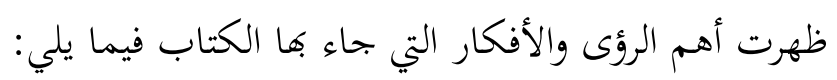

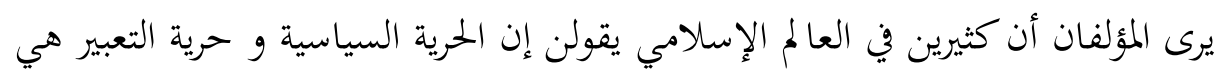

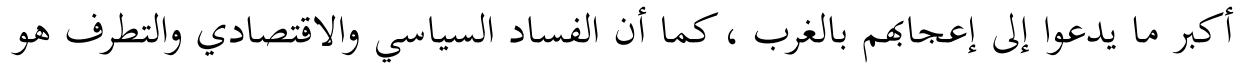
(०)

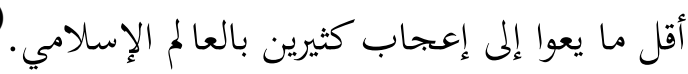

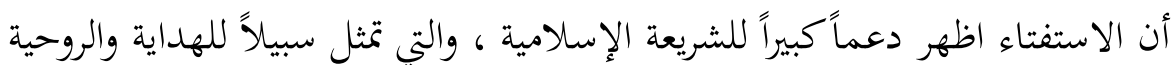

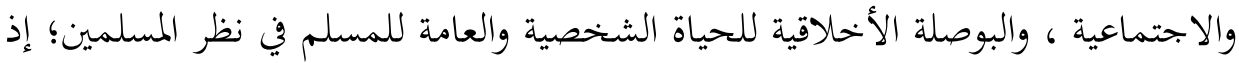

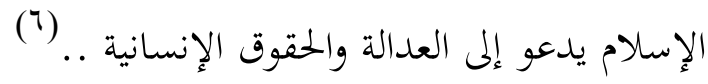

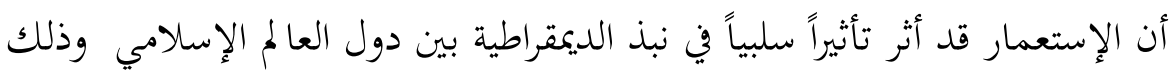

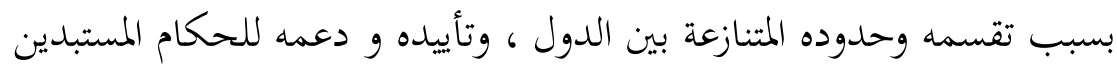
(1) العسكريين

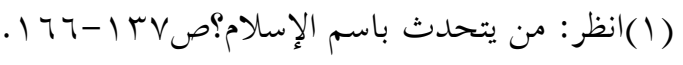

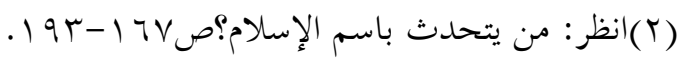

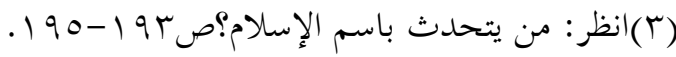

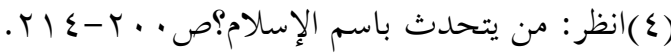

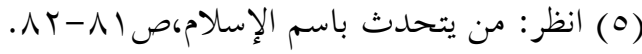

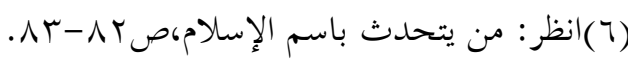


أن كثيراً من الدول ابتهت إلى الإسلام لفشل حكوماتم العلمانية أو القومية وفسادها. (r) ويرى المؤلفان أنه حتى مع القول بتطبيق الشريعة ،وجعلها الدستور للدولة ، إلا أها تختلف

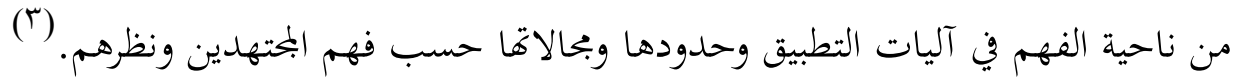
ويخلص المؤلفان إلى أنه لكي تعود أجواء التفاهم مع الغرب ، لابد ألد أن يقوم الغرب بأمور:

$$
\begin{aligned}
& \text { ا ـ ابداء المزيد من الاحترام والاهتمام بالعا لم الإسلامي والإسلام. } \\
& \text { r. أن لا ينتقصوا من مكانة البلاد العربية والإسلامية. }
\end{aligned}
$$

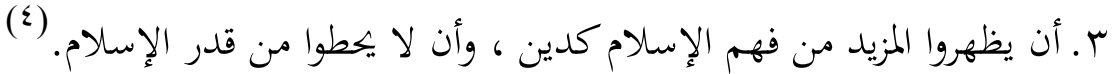
أن الأعمال الإرهابية لا ترتبط بالدين ،والأمثلة على ذلك كثيرة من أعمال العنف التي

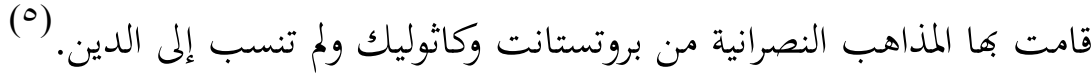
وأنه لا يلزم أن تكون الأعمال الإرهابية مدفوعة بالكراهية الدينية ، بل في الأكثر تكون

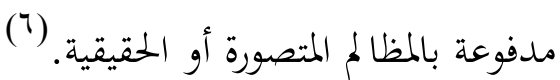

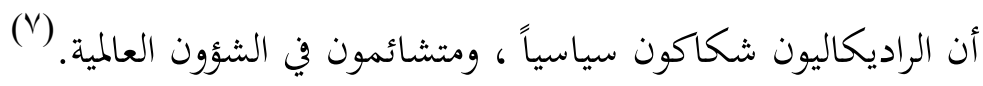

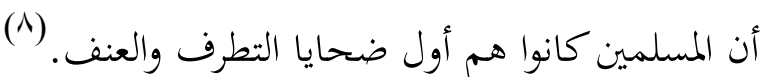
ويرى المؤلفان أن بعض الغربيين يخطئون حين لا يحترمون الثقافات الأخرى ، أو يجعلون

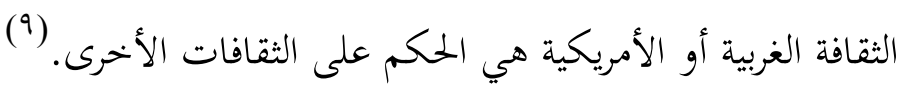

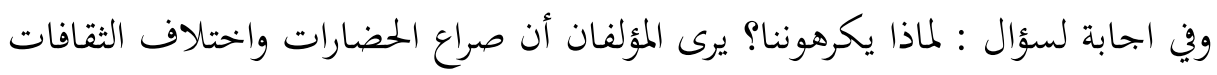
ليست السبب في ذلك، بل التأثير السيئ للسياسة الخارجية للولايات المتحدة الأمريكية

$$
\begin{aligned}
& \text { (1)انظر : من يتحدث باسم الإسلام،ص؟ م. }
\end{aligned}
$$

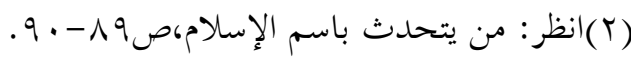

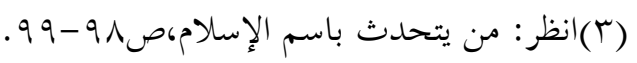

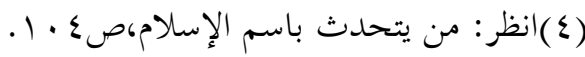

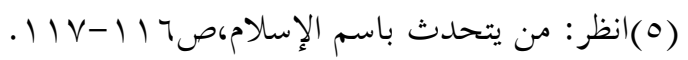

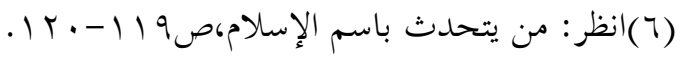

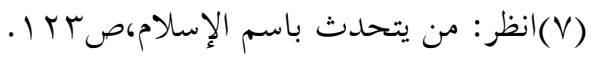

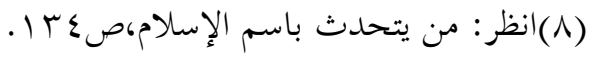

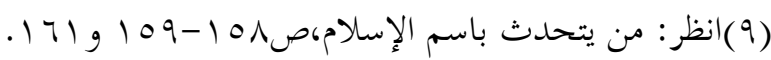


هي سبب لكراهية بدعمها للحكومات المستبدة ، وسكوقا عن الانتهاكات الكبرى

لمقوق الإنسان... (1)

ويرى أن الإسلام قد يكون سلاحاً قوياً في تكذيب الإرهابيين ، وتحديد انتشار الإرهاب،

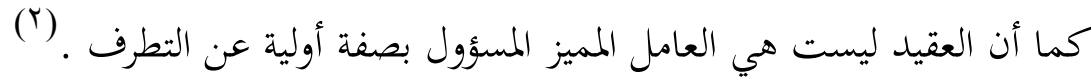

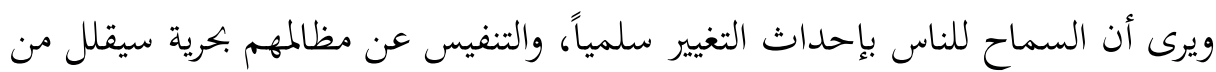

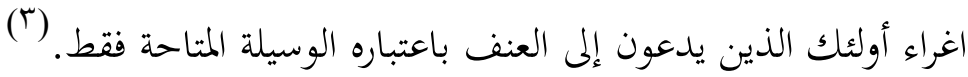

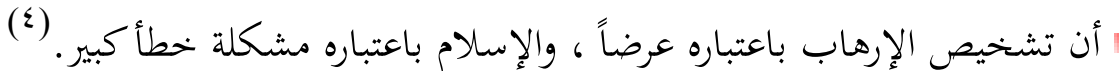

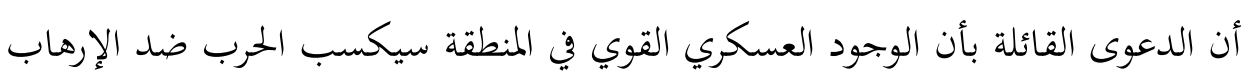

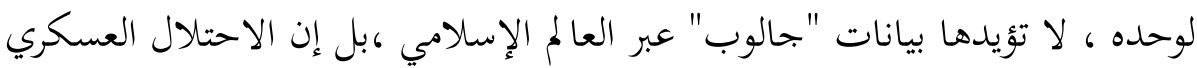

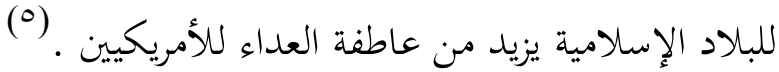

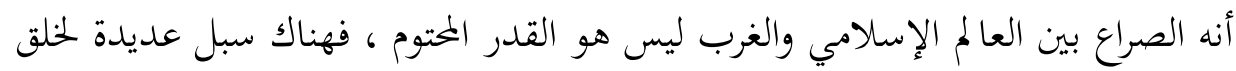

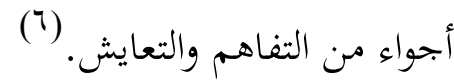

\section{المطلب الثالث: نظرة جون اسبيزتو للثقافة الإسلامية من خلال كتاب من يتحدث}

الكتاب نتاج ثقافي رائد في الاستفادة من الاستفتاءات ، وتحيرها ثقافياً ، وقد كانت فكرة

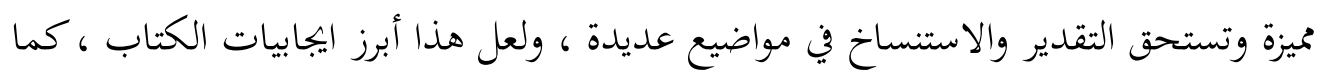
ظهرت العديد من مزايا الكتاب ومن ذلك :

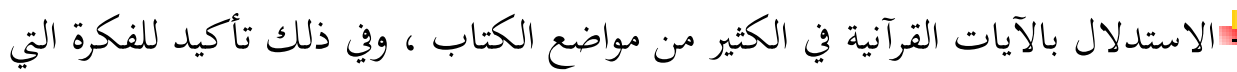
يريد الوصول إليها ن وأها حقيقة اسلامية . (v) \$ \$ دقة اسئلة الاستبيان وتعددها وصراحتها. (1)

$$
\begin{aligned}
& \text { (1)(انظر : من يتحدث باسم الإسلام،صو11). }
\end{aligned}
$$

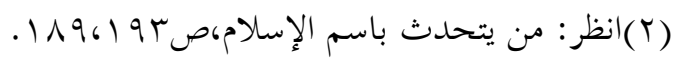

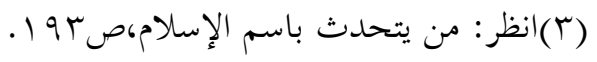

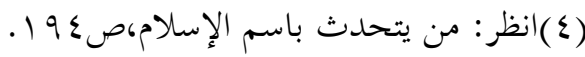

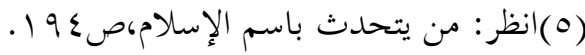

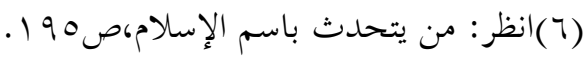

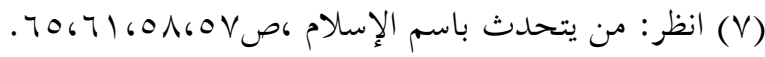


| بحاولة شرحه وتبسيطة للكثير من القضايا الإسلامية المهمة كالصلاة والصيام الحج ،

ومحاولة بياها للغرب. (r)

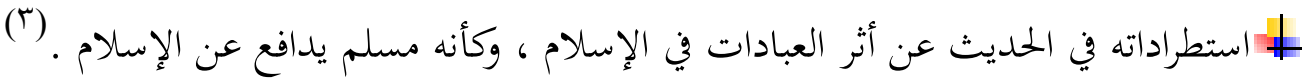

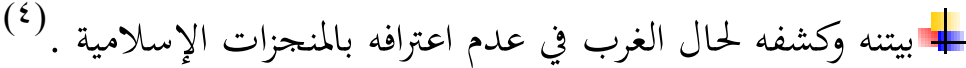

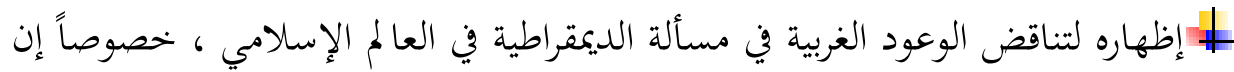

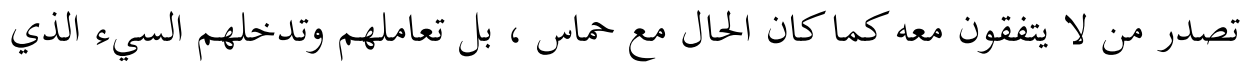

يخالف قواعد الديمقراطية . (ن)

\# كشفه للخلط الذي يقع فيه الغربين في انكارهم على المسلمين دعواقم لجعل الشريعة

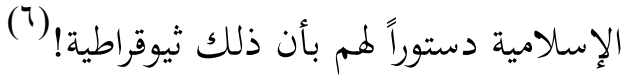

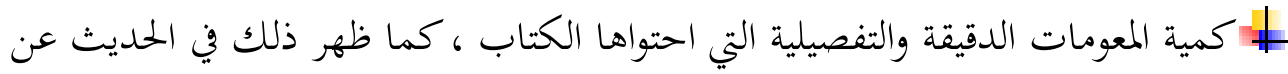

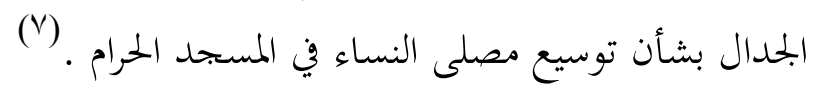

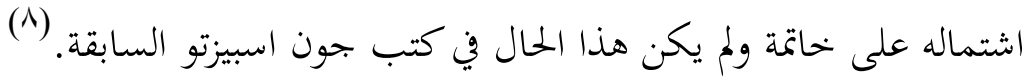

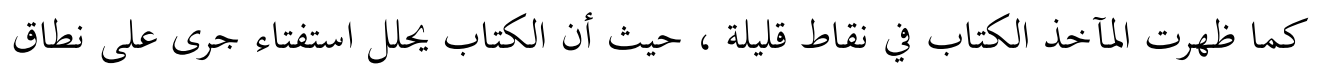
واسع ، وقد برزت اهم السلبيات في النقاط التالية:

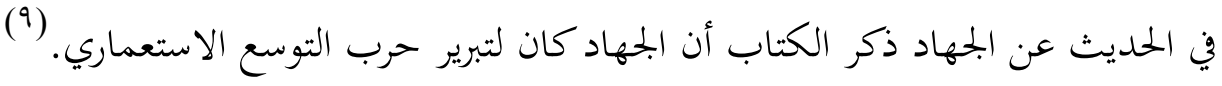

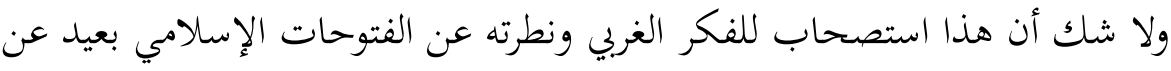

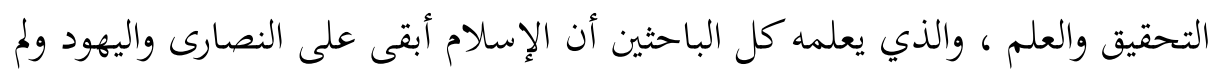

(1) انظر : من يتحدث باسم الإسلام ،صه ه- (1) و والأمثلة كثيرة.

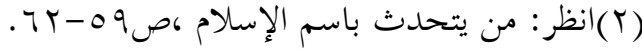

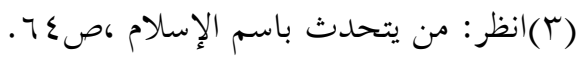

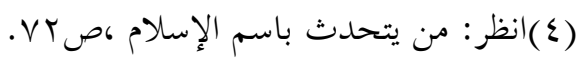

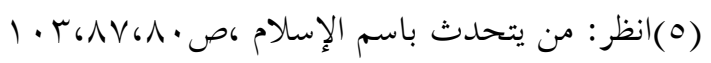

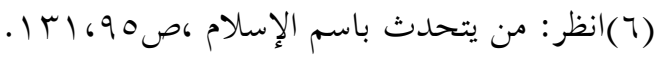

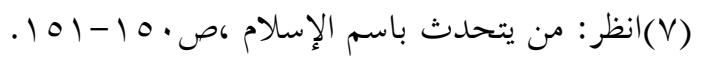

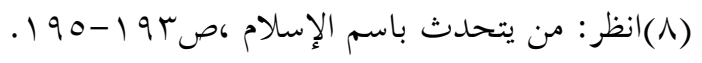

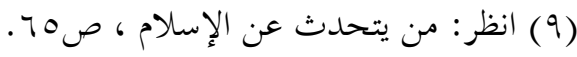


يكرههم على الإسلام كما لم يهجرهم أو يضطهدهم ، بل كانت رسالته الدعوة إلى دين الإسلام. تعليلاته لخلاف العلماء في آية السيف باتباع رغبات الملوك في ذلك!(') وذاك تحن آخر فالخلاف فيها قديم ، ولا مدخل للملوك والأمراء فيه.

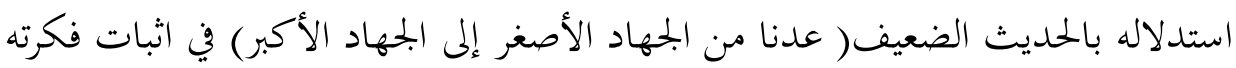

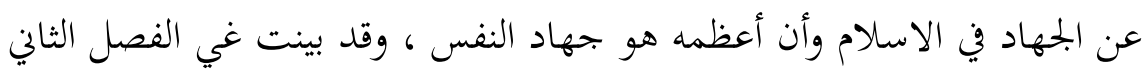
تضعيف العلماء لهذا الحديث.

تعميمه الذي لا يستند غلى برهان كقوله عن عمرو خالد أشهر واعظ ديني في العالم

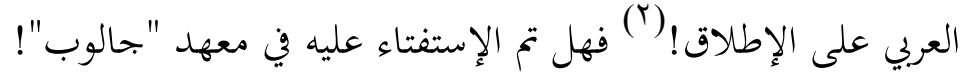

\section{الخاتمة}

الحمد لله الذي أكرمني بإتمام هذا البحث فله الفضل والشكر على منَّ به واسدى ، وفيما يلي بيان

$$
\text { لأهم النتائج والتوصيات: }
$$

1- يُعد جون اسبيزتو من الكتاب الذي تميزوا بقدر من الإنصاف والموضوعية ، مع وضوح في

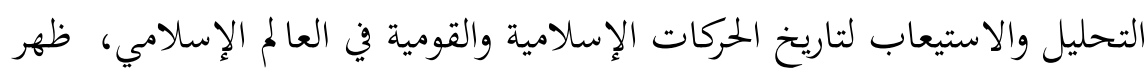

$$
\text { ذلك في العديد من كتبه التي ذكرت معنا في هذا البحث. }
$$

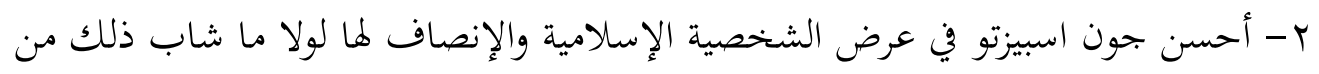

جعله للثقافة الغربية الميزان في ذلك ، وقرب المجتمعات الإسلامية منها ، في قضايا

$$
\text { كبرى مثل الديمقراطية والحرية وغيرهما. }
$$

$$
\text { r- يعد كتاب الخطر الإسلامي رصد لواقع الحركات الإسلامية من بواكيرها حتى أحداث }
$$

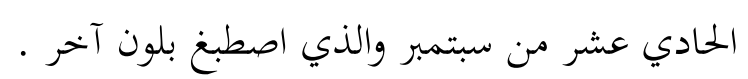

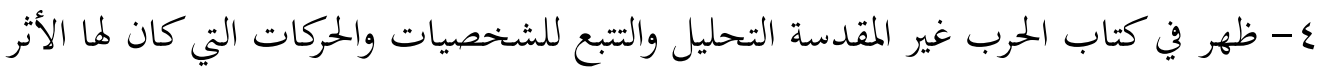

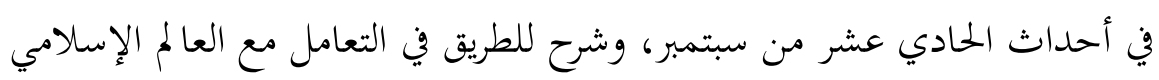

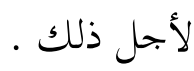

$$
\text { (1) (1) انظر: : من يتحدث عن الإسلام ، صلآ. }
$$


ه- في كتاب من يتحدث باسم الإسلام نقلة كبرى في اظهار حقيقة العالم الإسلامي

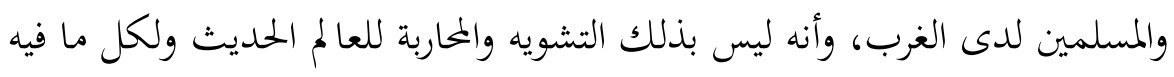

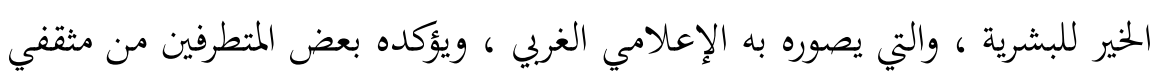

$$
\text { الغرب بتحاه الإسلام. }
$$

צ- يصرح جون اسبيزنو في جميع كتبه بأن الحل الأمثل في التعامل مع العالم الإسلامي يكون

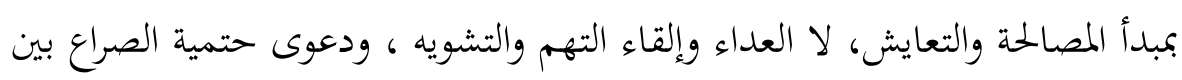

$$
\text { - ثانياً أهم التوصيات: }
$$

1- أقامة المؤتمرات في بيان منهج وطرق المستشرقين المنصفين ، وكيفية التعامل معهم.

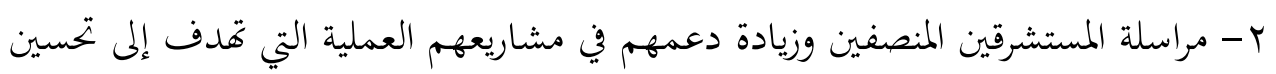

$$
\text { صورة المسلمين في العالم. }
$$

r- استنساخ بحربة استبيان "جالوب" في خدمة العديد من القضايا الإسلامية الكبرى، لما للغة

$$
\text { الأرقام من أثر علمي وثقافي. }
$$

هذا ما يسر الله اتمامه في هذا البحث ، والله أعلم وصلى الله وسلم وبارك على نبينا محمد وعلى آله

$$
\text { وصحبه وسلم. }
$$

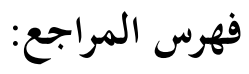

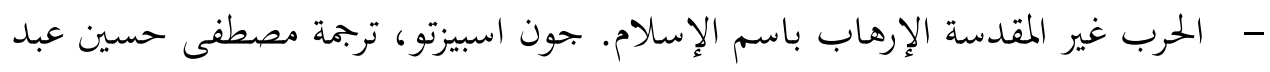

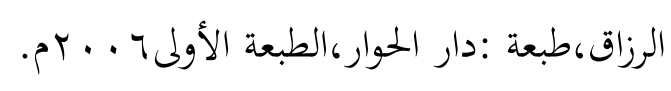

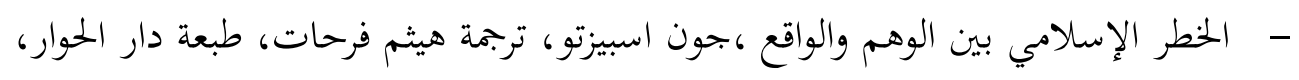

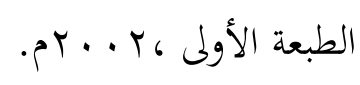

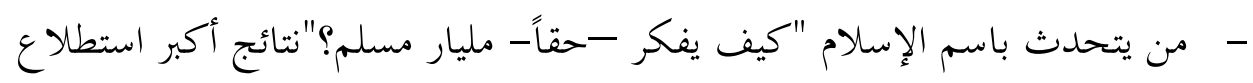

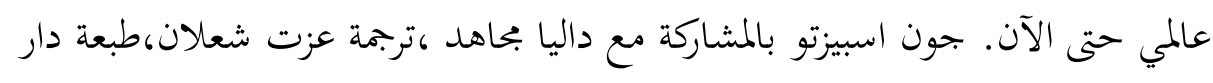

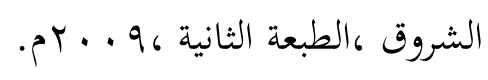

